\title{
High resolution mapping of sediment organic matter from acoustic reflectance data
}

\author{
Natalia Serpetti • Mike Heath • \\ Malcolm Rose $\cdot$ Ursula Witte
}

Received: 19 May 2011/Revised: 20 October 2011/Accepted: 25 October 2011/Published online: 29 November 2011

(C) Crown Copyright 2011

\begin{abstract}
Spatial mapping of the marine environment is challenging when the properties concerned are difficult to measure except by shore-based analysis of discrete samples of material, usually from sparsely distributed sites. This is the case for many seabed sediment properties. We developed an indirect approach to mapping the organic content of coastal sediments from hydro-acoustic reflectance data. The basis was that both organic matter and acoustic reflectance are related to sediment type and grain size composition. Hence there is a collateral relationship
\end{abstract}

Handling editor: Koen Martens

N. Serpetti $(\bowtie) \cdot$ M. Heath · M. Rose

Marine Scotland - Science Laboratory Aberdeen,

375 Victoria Road, PO Box 101, Aberdeen AB11 9DB, UK

e-mail: Serpettin@gmail.com

M. Heath

e-mail: m.heath@strath.ac.uk

M. Rose

e-mail: M.Rose@marlab.ac.uk

\section{N. Serpetti · U. Witte}

Oceanlab, Institute of Biological and Environmental

Sciences, Ecology, University of Aberdeen, Newburgh,

Aberdeenshire AB41 6AA, UK

e-mail: u.witte@abdn.ac.uk

Present Address:

M. Heath

Department of Mathematics and Statistics, University of Strathclyde, Livingstone Tower, Richmond St,

Glasgow G1 1XH, UK between organic matter content and reflectance properties which can be exploited to enable high resolution mapping. We surveyed an area of seabed off the east coast of Scotland using a vessel mounted single beam echosounder with RoxAnn signal processing. Organic carbon, nitrogen and phytoplankton pigment contents were then measured in material from grab and core samples collected at intervals over a year. Relationships between the organic components and hydroacoustic characteristics were derived by general additive models, and used to construct high resolution maps from the acoustic survey data. Our method is an advance on traditional interpolation techniques sparse spatial data, and represents a generic approach that could be applied to other properties.

Keywords Single beam RoxAnn - Ground truthing survey $\cdot$ Hardness $\cdot$ Roughness $\cdot$ Total organic carbon (TOC) - Total nitrogen (TN) $\cdot$ Chlorophyll- $a$

Pheophytin- $a \cdot$ Scotland $\cdot$ UK

\section{Introduction}

Habitat mapping is an important prerequisite for the sustainable management of marine ecosystems. Maps are required to assess environmental quality, develop management zoning schemes within marine protected areas, and to evaluate the impacts of disturbance (ICES, 2005). Predictive models of physical and biological information and full coverage spatial 
distribution maps are increasingly demanded but generally lacking (ICES, 2005; Young, 2007). Full coverage habitat maps can be created from point sampling data using statistical interpolation methods (e.g. 'Kriging') and/or by developing statistical models, where physical, chemical and biological properties (e.g. sediment grain size and benthos community) are linked to 'full coverage' information (e.g. Digital Elevation Models and acoustic ground discrimination data) (Verfaillie et al., 2006; Degraer et al., 2008).

Knowledge of the seabed coastal sediments and morphology off the east coast of Scotland (North Sea) is largely based on 1:250,000 scale maps produced from core and dredge surveys (several $\mathrm{km}$ between samples) and seismic data collected by the British Geological Survey (BGS) in the 1970s and 1980s (e.g. Baxter et al., 2008). These indicate that the inshore sediments in the area are relatively uniform and composed of sand and gravel. Muddy sediments are shown as located offshore in deeper water and around the major estuaries to the north and south. However, recent hydro-acoustic surveys (Serpetti et al., 2011) have shown that sediments in a section of the inshore waters are actually composed of a wider range of sediment types ranging from muddy sand to boulders and rock.

The organic matter content and biological communities of seabed sediments are strongly related to grain size characteristics (McBreen et al., 2008), and sediment porosity and permeability (Winterwerp \& Van Kesteren, 2004; Janssen et al., 2005), although inconsistencies between boundaries defined by the sediment classification schemes, chemical characteristics and biological communities are often found. An alternative is to use statistical approaches to relate continuous physical and chemical characteristics of sediments to categorical biological assemblages (Verfaillie et al., 2006; Degraer et al., 2008; McBreen et al., 2008).

In this article, we capitalise on the statistical relationships between organic composition of sediments and their physical properties, to develop Generalised Additive Models (GAMs) linking organic matter content to data generated by an Acoustic Ground Discrimination System (AGDS; RoxAnn), and thereby produce full coverage spatial distribution maps of sediment total organic carbon, total nitrogen, chlorophyll and pheophytin. The purpose was to establish a basis for planning an investigation of the environmental processes that regulate nutrient fluxes across the sediment-water interface, and provide the opportunity to upscale results from in-depth investigations that are only possible at a limited number of discrete stations.

In areas where the seabed is too deep for light to penetrate to the sediment surface and support algal growth, and in the absence of chemosynthetic production, the sole source of organic matter (OM) is sedimentation from the photic zone above. In shallow shelf waters up to $50 \%$ of phytoplankton production can settle to the seabed (Jørgensen et al., 1990; Canfield et al., 1993; Wollast et al., 1998), providing a rich food supply for the benthic community (Conley \& Johnstone, 1995). Most of this particulate organic material is mineralised in the sediment, enriching pore water nutrient concentrations and recycling nutrients back into the water column (Rutgers Van Der Loeff, 1980; Ehrenhauss et al., 2004). The organic matter supply is then mostly controlled by the primary production rate in the surface waters, the depth through which particulate material must settle, and the bulk sedimentation rate (Calvert, 1987). In areas where the seabed is deeper than the base of the photic zone, organic matter concentrations in sediment are generally positively correlated with the proportion of fine-grained material, (Winterwerp \& Van Kesteren, 2004), decrease with the median grain size (Lohse et al., 1995), and can be influenced by topographical features of sediment surface (Janssen et al., 2005). In shallower waters, additional factors are involved including resuspension events and terrestrial inputs (Jenness \& Duineveld, 1985; Ogrinc et al., 2005).

\section{Materials and methods}

The study area, of $\sim 180 \mathrm{~km}^{2}$, was located between latitude $56^{\circ} 54^{\prime} \mathrm{N}$ and $57^{\circ} 03^{\prime} \mathrm{N}$ off Stonehaven, northeast Scotland, UK. The sediment characteristics were highly variable throughout the area ranging from muddy sand to boulders and rock, and the depth ranged between 14 and $57 \mathrm{~m}$ (Fig. 1a, b). A single beam RoxAnn acoustic survey was carried out in the study area and a supervised classification scheme discriminated 12 sediment classes (Fig. 1a) (Serpetti et al., 2011). 


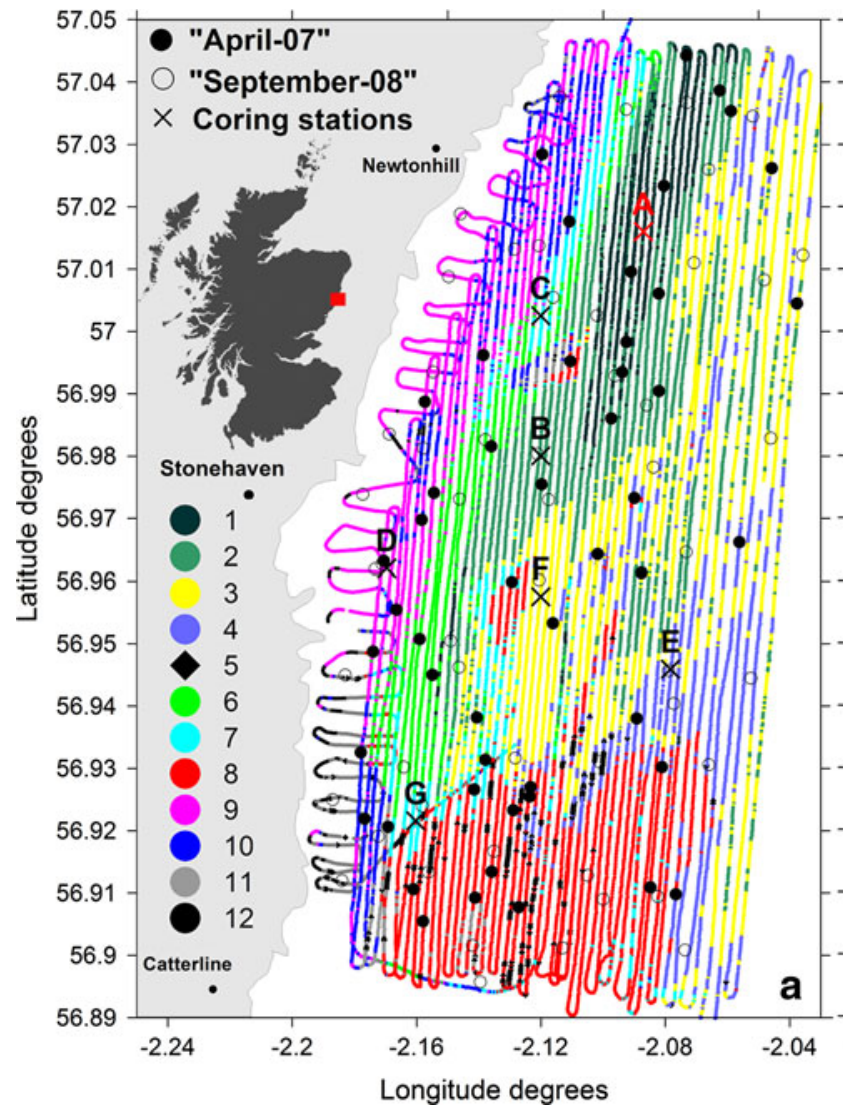

Fig. 1 a RoxAnn supervised map identifying 12 sediment classes raging from muddy sands to sediment with pebbles and cobbles (from Serpetti et al., 2011). Class 1, smooth, very fine muddy sand; class 2, smooth, very fine-fine muddy sand; class 3 , smooth, medium sand; class 4, smooth, gravelly medium-coarse sand with pebbles; class 5, boulders; class 6 , slightly rippled, fine muddy sand with ophiuroids present; class 7 , slightly rippled,

Acoustic roughness and hardness variables

Single beam RoxAnn acoustic surveys (SIMRAD EK60 $38 \mathrm{kHz}$ echosounder) were carried out in the study area by FRV 'Scotia' (December 2006) and RV 'Clupea' (March 2008). The first survey consisted of a set of 50 parallel tracks orientated along the axis of the tidal ellipse, which was approximately parallel to the coast. At the survey speed of the vessel, the mean along-track distance between beam foot-print centres of successive acoustic samples was $45 \mathrm{~m}$, and the tracks were on average $160 \mathrm{~m}$ apart. The duration of the survey was $54 \mathrm{~h}$, and the total distance covered by the vessel was $826 \mathrm{~km}$. The most inshore track by the vessel came within $1 \mathrm{~km}$ of the shore, which was the closest that the vessel was able to approach at the

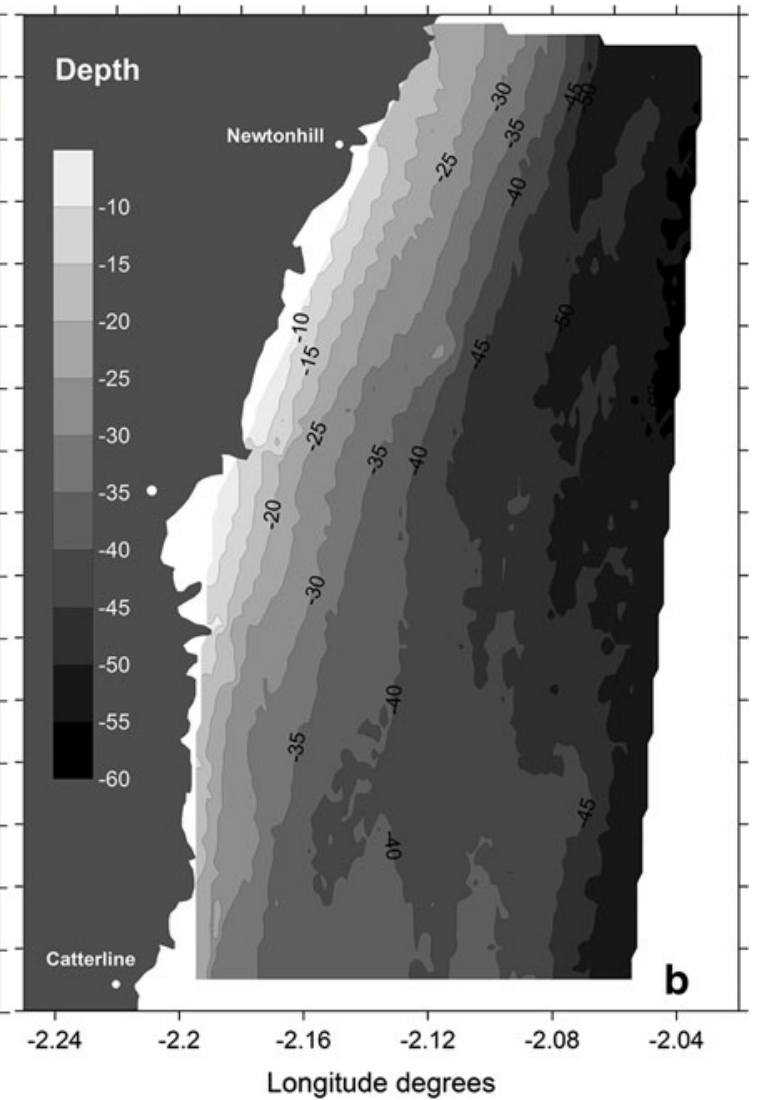

fine-medium sand with ophiuroids present; class 8, gravelly muddy sand with pebbles and cobbles with Alcyonium digitatum present; class 9, rippled, fine sand; class 10, rippled, mediumcoarse sand; class 11, gravelly muddy sand with cobbles and high concentration of $A$. digitatum; class 12 , gravelly muddy sand with boulders and high concentration of A. digitatum. b Bathymetry map. For map details see Serpetti et al. (2011)

survey speed of 8 knots. The second survey was carried out, at the same average speed, to collect data from the near-shore zone during which transects were conducted perpendicular to the coast line and overlapped with the first acoustic survey tracks. The acoustic systems saved data on indices of seabed roughness and hardness at $10 \mathrm{~s}$ intervals along the survey track in both surveys, resulting in a combined data set of hydro-acoustic roughness and hardness indices at approximately 19,600 locations (Serpetti et al., 2011).

Sediment sample collection

Spatial sampling surveys of sediments were carried out in April 2007 and September 2008 by the research 
vessels RV 'Clupea' and RV 'Alba na Mara', respectively (Fig. 1). The aim of these surveys was to obtain spatially distributed grab samples of the seabed sediment for measuring physical (median grain size, percentage of mud content, sorting level, skewness and kurtosis) and chemical properties (total organic carbon (TOC\%) and total nitrogen (TN\%) and chlorophyll- $a$ (Chl- $a$ ) and pheophytin- $a$ (Pheo- $a$ ) content (Chl- $a$ and Pheo- $a$ only in the second survey)). During the first survey, fifty grab sampling locations were chosen by random assignment within each of nine spatial strata identified by a preliminary unsupervised assessment of the AGDS data (Serpetti et al., 2011) with 3 locations per class plus 23 in proportion to their data abundance in the study area. During the second survey, a further 54 locations were sampled and an underwater television system towed for 1-2 min at each station. On both occasions, seabed samples were collected with a Day grab $\left(0.1 \mathrm{~m}^{2}\right)$. On recovery of the grab, overlying seawater was first syphoned off and a photograph taken of the exposed sediment. A nominal $5 \mathrm{~cm}$ long $\times 2.5 \mathrm{~cm}$ diameter sub-sample was then removed by means of a core tube pressed into the grab material and frozen in a sealed plastic bag for grain size and chemical analyses.

In addition to the grab sampling surveys described above, core sampling was carried out at approximately monthly intervals between June-08 and July-09. On each occasion, three replicate core samples were collected with a MiniMuc corer deployed from the vessel 'Temora' at seven locations (A, B, C, D, E, F and $\mathrm{G})$ characterised by different sediment properties and depths in the study area (Fig. 1). The locations coincided with seven of the grab sampling sites in the September08 survey. A total of 174 cores were collected and sliced at $1 \mathrm{~cm}$ intervals to create vertical profiles of subsamples for analysis. TOC and TN concentrations were measured only in the upper $1 \mathrm{~cm}$ slice of each core, whilst pigments were measured in $0-1 \mathrm{~cm}$ and $1-5 \mathrm{~cm}$ slices. Pigment data from the two depth horizons in the cores were combined to give data in the upper $5 \mathrm{~cm}$ so as to correspond with the grab sample data.

Grain size analysis

Sediment samples were freeze-dried and sieved in the laboratory using a sieve shaker through 8, 4, 2 and $1.4 \mathrm{~mm}$ mesh for $7 \mathrm{~min}$; each sieved fraction was weighed to $0.01 \mathrm{~g}$. Grain size smaller than $2 \mathrm{~mm}$ was analysed by laser granulometry using a 'Mastersizer $2000^{\prime}$ instrument (Malvern Instruments Ltd., UK). The 2.0-1.4 mm fraction from both sieving and laser diffraction were compared to ensure that a representative sub-sample had been used in the Mastersizer 2000. The cumulative weight percentages below each sieve fraction were calculated and combined with the cumulative volume percentage for each size range measured by the instrument, which had been adjusted to account for the $>1.4 \mathrm{~mm}$ fraction, to obtain a full particle size range from 0.49 to $8000 \mu \mathrm{m}$. For each sediment sample, median grain size, mud content, sorting level, skewness and kurtosis were then derived.

Sediments were categorised according to grain size using a combined classification based on the UddenWentworth scale (Udden, 1914; Wentworth, 1922) and Folk's classification system (Folk, 1954). As for the Udden-Wentworth scale, the classification was based on the median grain size distinguishing sediment from very fine sand to boulders. However, as for Folk's classification system, a sand:mud ratio between 1:1 and 9:1 defined 'muddy' sediments (sand refers to fractions smaller than $2 \mathrm{~mm}$; mud refers to fractions smaller then $63 \mu \mathrm{m}$ ), while 'slightly gravelly' or 'gravelly' sediments were defined for a percentage of gravel between $1-5 \%$ and $5-30 \%$, respectively.

Total organic carbon and total nitrogen analysis

Percentages by weight of total organic carbon and total nitrogen (TOC\% and $\mathrm{TN} \%$ ) in the freeze-dried sediment samples were measured using a ThermoQuest Flash EA 1112 elemental analyser, which uses a combustion method to convert the sample elements to simple gases $\left(\mathrm{CO}_{2}, \mathrm{H}_{2} \mathrm{O}\right.$ and $\left.\mathrm{N}_{2}\right)$. For the total organic carbon, the samples were acidified with $\mathrm{HCl}$ in silver cups prior to the analysis to remove the inorganic carbon fraction (ThermoQuest FlashEA 1112 elemental analyser operating manual, 1999).

Chlorophyll- $a$ and pheophytin- $a$ analysis

Pigments in weighed sub-samples of the freeze-dried sediment were extracted by soaking in a known volume of $90 \%$ buffered acetone for $24 \mathrm{~h}$, in the dark at $3-5^{\circ} \mathrm{C}$ in a centrifuge tube. During this time the samples were regularly shaken and then centrifuged for $10 \mathrm{~min}$ at $3000 \mathrm{rpm}$. For each sample the fluorescence of the supernatant before and after acidification 
was measured with a fluorometer (Turner 10-AU) which had previously been calibrated against a Chl- $a$ standard. For pigment extractions and analysis a modified method expired by Lorenzen (1967) and Arar \& Collins (1997) was used. The Chl- $a$ and Pheo$a$ concentrations in each sample were then calculated according to Strickland \& Parsons (1972) and referenced to the weight of sediment used for the extraction.

\section{Chemical contents modelling}

ANOVA tests were used to analyse the significance of variations between measurements made on the sequential samples collected from each site over the 14 month core sampling period, and between the measurements made in cores and the spatially and temporally coincident grab samples collected during the September-08 survey.

Longitudes and latitudes of the grab and core sample locations were used to extract, using a nearest neighbour algorithm, the corresponding roughness, hardness and depth values in the AGDS dataset. Graphical exploratory techniques were used to check for outliers, while the variance inflation factor (VIF) and the Pearson correlation were used to check for collinearity among the explanatory covariates. VIF values higher than 3 (Zuur et al., 2010), or higher than 5-10 (Montgomery \& Peck, 1992) are considered the cut-off levels, while Pearson correlation values greater than 0.8 indicate a clear linear relationship between two variables (Zuur et al., 2007). Generalised Additive Modelling (GAM) was then used to relate the response variables (TOC\%, TN\%, Chl- $a$ and Pheo- $a$ ) to the seabed sediment acoustic properties (roughness, hardness and depth) and to the sampling month. The collinearity between the smoothing terms of the GAM was also analysed using the concurvity function (Wood, 2003). To avoid model over-fitting the maximum number of the smoothing parameters $(k)$ was fixed (Cawley \& Talbot, 2010).

\section{Model cross-validations}

Model validations were carried out by analysing the normality, present in the model assumption, plotting the theoretical quantiles versus standardised residuals (Q-Q plots), and the frequency distributions of residuals. Collinearity was checked using the Pearson correlation coefficient and homogeneity of variance by plotting residuals versus fitted values (Zuur et al., 2010). Further model validations were performed by dividing the grab and core sample dataset into a subset used for fitting the GAMs, and an independent validation subset to which predictions by the fitted GAMs were compared. Because sediment pigment contents were measured only during the second grab sampling survey, different proportions of all datasets (271 and 225 data points between core and grab samples for TOC (and TN) and pigments, respectively) were selected for fitting and validation of TOC\% and TN\% (70\% for the fitting subset (190 samples) and $30 \%$ for the validation subset (81 samples)) and for Chl- $a$ and Pheo- $a$ (90\% for the fitting subset (202 samples) and $10 \%$ for the validation subset (23 samples)). The independent validation subsets were a random selection from four strata defined by the AGDS roughness and hardness at the grab and core sampling locations. GAM predictions for the organic content at the validation sample locations were compared with the actual measurements by Pearson correlation. The correlations were calculated for three and five independent random subsamples of the datasets for TOC\% and TN\% and for Chl- $a$ and Pheo- $a$, respectively. All analysis and statistical tests were carried out using the software R version 2.6.2 using the libraries mgcv and akima.

\section{Full coverage modelling spatial maps}

The fitted GAMs relating organic matter content to AGDS roughness and hardness were used to predict sediment chemical content and the corresponding relative standard errors of the predictions for the roughness and hardness of each observation in the RoxAnn dataset ( $\sim 19,600$ points), each of which had an associated latitude and longitude. Predicted values and relative standard errors were then spatially interpolated to a cylindrical projection geographical grid for contouring using the 'Kriging' method (software package Surfer ${ }^{\mathrm{TM}}$ ). The grid cell geometry was $0.0017 \times 0.0017$ decimal degrees, which at the latitude of the study site corresponded to $\sim 100 \mathrm{~m}$ in the east-west direction and $185 \mathrm{~m}$ in the north-south direction. This corresponded approximately to the raw data density from the AGDS (45 $\mathrm{m}$ along-track (southwest-northeast) distance between data points, and $160 \mathrm{~m}$ between tracks (northwest-southeast). The 
'Kriging' interpolation scheme employed either spherical or linear variograms with a nugget effect. The most appropriate variogram was chosen for each parameter to be mapped based on the match to the theoretical and experimental variograms (e.g. Verfaillie et al., 2006). The relative standard errors of the GAMs predictions at each AGDS data point represented the error of the fit of the GAMs with respect to the original grab data used to develop the models.

The 'Kriging' interpolation process also generated a source of error that represents the spatial distribution of the fit of the interpolated surface to the predictions from the GAM. To assess the contribution of this source of error we extracted the 'Kriging' standard deviations at each grid node and transformed these to relative standard errors by dividing the estimated values by the square root of the number of data points used for the estimations at each node. This number was in principle variable over the grid but because of the high density of the data the number of points per grid node involved in the gridding process was limited to 64 by the 'Kriging' process.

Spatial maps of directly interpolated grab sample TOC data

A spatial distribution map of sediment TOC and associated standard error, chosen as an example, was derived with direct interpolation from the point location grab samples, to compare with the map produced by application of the fitted GAM to the acoustic data fitting. We used the same 'Kriging' method with a spherical variogram and a nugget effect as applied to grid the TOC GAM model output data. The grid cell geometry was $0.0015 \times 0.0015$ decimal degrees. In this case, the error of the gridding process is the only source of error. In the same way as described for the full coverage maps, we transformed the standard deviation grid to relative standard error: however, in this case the variogram used all the grab samples available (97) as the maximum number of points involved in the gridding process within the variogram distance at each grid node. To estimate the number of grabs involved in the interpolation process at each grid node we used a nearest neighbour algorithm within the maximum distance defined by the variogram.

\section{Results}

Modelling chemical element concentrations

All the organic matter variables were highly correlated with each other, and with the sediment mud content (Table 1). However, their relationships with median grain size were not linear (Fig. 2), showing an initial decrease of TOC\% (chosen as an example) with a

Table 1 Collinearity table. Pearson correlation values between response variables (TOC, TN, chlorophyll- $a$ (Chl- $a$ ) and pheophytin- $a$ (Pheo- $a)$ ), explanatory variables (roughness,

hardness and depth) and grain size properties (median grain size, percentage of mud content, sorting level, skewness and kurtosis)

\begin{tabular}{|c|c|c|c|c|c|c|c|c|c|c|c|}
\hline & $\mathrm{TN}$ & Chl- $a$ & Pheo- $a$ & Roughness & Hardness & Depth & $\begin{array}{l}\text { Median } \\
\text { grain size }\end{array}$ & $\begin{array}{l}\text { Mud } \\
\text { content }\end{array}$ & $\begin{array}{l}\text { Sorting } \\
\text { level }\end{array}$ & Skewness & Kurtosis \\
\hline TOC & 0.98 & 0.57 & 0.71 & -0.53 & -0.16 & 0.48 & -0.02 & 0.91 & 0.43 & 0.34 & -0.19 \\
\hline $\mathrm{TN}$ & & 0.59 & 0.74 & -0.52 & -0.09 & 0.48 & 0.02 & 0.90 & 0.50 & 0.29 & -0.24 \\
\hline Chl- $a$ & & & 0.91 & -0.27 & -0.32 & 0.20 & -0.20 & 0.60 & 0.06 & 0.25 & -0.04 \\
\hline Pheo- $a$ & & & & -0.37 & -0.24 & 0.31 & -0.14 & 0.73 & 0.27 & 0.25 & -0.14 \\
\hline Roughness & & & & & -0.01 & -0.93 & 0.14 & -0.51 & -0.20 & 0.00 & -0.12 \\
\hline Hardness & & & & & & 0.18 & 0.49 & -0.23 & 0.61 & -0.37 & -0.04 \\
\hline Depth & & & & & & & -0.03 & 0.45 & 0.34 & -0.07 & 0.13 \\
\hline Median grain size & & & & & & & & -0.21 & 0.45 & 0.12 & -0.26 \\
\hline Mud content & & & & & & & & & 0.38 & 0.32 & -0.19 \\
\hline Sorting level & & & & & & & & & & -0.23 & -0.40 \\
\hline Skewness & & & & & & & & & & & 0.07 \\
\hline
\end{tabular}

High correlation values are indicated by values greater than $0.6-0.7$ 


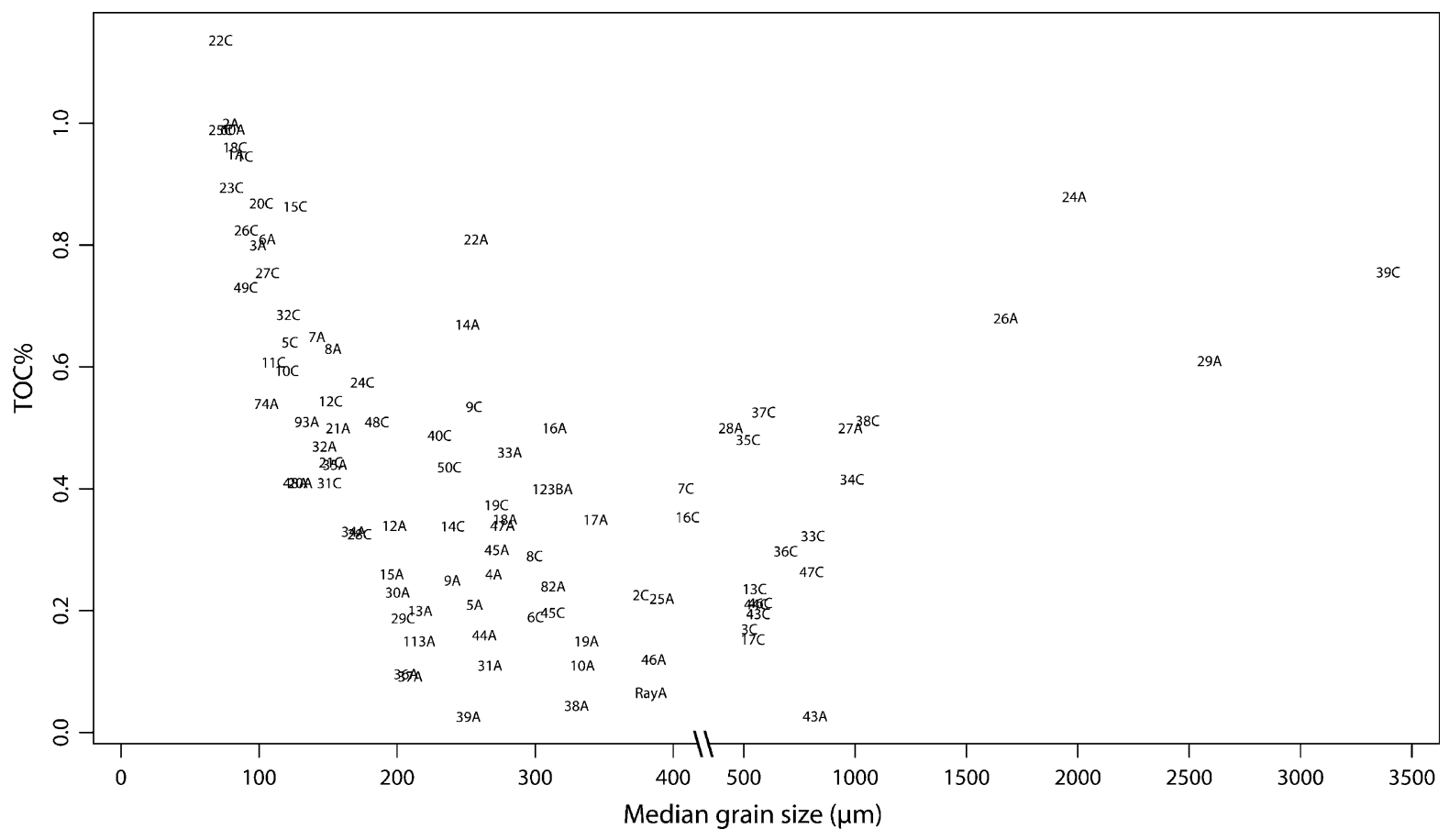

Fig. 2 Percentage of total organic carbon as a function of median grain size $(\mu \mathrm{m})$. Grab sample numbers collected during the first (April-07, vessel 'Clupea') and the second (September-08,

corresponding increase of median grain size up to $\sim 400 \mu \mathrm{m}$, and increasing thereafter.

Of the proposed explanatory variables, roughness and depth were highly inversely and linearly related $(r=0.93$, Table 1$)$ and also the VIF analysis showed a correlation between the covariates roughness (8.9), hardness (1.4) and depth (9.1). After discarding the depth covariate, which had the highest VIF value, no remaining correlation was detected between the explanatory variables roughness and hardness. Depth was therefore excluded from the analysis on the grounds of being the least descriptive of seabed characteristics.

The exploratory analysis of the organic content variables identified one outlier for total organic carbon and total nitrogen in the first grab sampling survey that was removed.

ANOVA tests did not identify significant seasonal variations in the core sample dataset for TOC\% and TN\% $(P>0.5)$. In contrast, highly significant differences were found for the pigments Chl- $a$ and Pheo- $a(P<0.001)$ with higher concentrations in summer compared to winter months. Moreover, no significant differences were found between TOC\% vessel 'Alba na Mara') surveys are followed by the letters $C$ and $A$, respectively

and TN\% measured in the $0-1 \mathrm{~cm}$ depth core and grab samples collected at the same locations $(P>0.5)$. In contrast, pigment concentrations were significantly higher in the $0-1 \mathrm{~cm}$ core sample horizons than in the corresponding $0-5 \mathrm{~cm}$ grab samples. However, 0-5 cm pigment concentrations in the core and corresponding grab samples were not significantly different $(P<0.05)$.

The optimum GAMs for the chemical properties were a Gaussian fit with the following forms:

$y \sim s$ (Roughness, Hardness, $k=6, \mathrm{fx}=$ FALSE $)$, $y=\mathrm{TOC} \%$ and $\mathrm{TN} \%$

$y \sim s$ (Roughness, Hardness, $k=6$, fx $=$ FALSE)

$+s$ (Month),

$y=\mathrm{Chl}-a$ and Pheo $-a$

where $s$ represents a regression spline smoother, and $k$ the maximum degrees of freedom allowed. These models explained 54.8, 48.4, 65.3 and $64.1 \%$ of the deviance for TOC\%, TN\%, Chl- $a$ and Pheo- $a$, respectively, and were all highly significant at $P<0.001$. The estimated degrees of freedom were from 4.8 to 4.9 for all the bio-dimensional smoothers 
roughness-hardness and 7.2 and 5.1 for the seasonality trends of Chl- $a$ and Pheo- $a$, respectively.

The concurvity test did not show collinearity between the smoothed explanatory variables included in the final models.

\section{Model cross-validations}

Predictions from the GAMs fitted to the randomly selected subsets of the data, were in all cases significantly correlated with the remaining independent validation data (Table 2). Hence, we assert the validity of the GAMs as descriptors of the organic matter content of the sediments with respect to AGDS roughness and hardness.

\section{Predicting chemical element concentrations}

The concentrations of carbon, nitrogen and pigments were predicted by the fitted GAMs for each of the AGDS data points (hardness and roughness) and for the month of May for Chl- $a$ and Pheo- $a$ (Fig. 3). The results showed that the highest values $(0.7-0.9 \%$, $0.07-0.09 \%, 2.6-3 \mu \mathrm{g} \mathrm{g}^{-1}$ and $9-10 \mu \mathrm{g} \mathrm{g}^{-1}$, for TOC\%, TN\%, Chl- $a$ and Pheo- $a$, respectively) corresponded with smooth, soft sediments (low roughness

Table 2 Deviance explained (\%) by GAMs for the prediction sub-sets (three for TOC $\%$ and TN\% and five for Chl- $a$ and Pheo- $a$ ) and Pearson correlations (\%) between fitted and observed sub-sets

\begin{tabular}{lll}
\hline & Dev. expl. (\%) & Correlation (\%) \\
\hline TOC & 54.6 & 68 \\
& 56.8 & 65 \\
& 57.9 & 60 \\
Chl- $a$ & 65.4 & 67 \\
& 62.3 & 63 \\
& 63.5 & 74 \\
& 63 & 49 \\
TN & 67.6 & 63 \\
& 48.6 & 61 \\
& 50.5 & 61 \\
Pheo- $a$ & 53 & 45 \\
& 65.4 & 50 \\
& 57.8 & 51 \\
& 62.9 & 56 \\
& 57.9 & 80 \\
\hline
\end{tabular}

and hardness). In addition, all response variables showed a secondary peak in the interior of the roughness-hardness domain space (hardness $\sim 1.2$, roughness $\sim 0.75$ ). In the case of the pigment variables, these also showed significant seasonal variation with elevated concentrations in summer months (May-August) for mean values of roughness and hardness (Fig. 4).

The relative standard errors of the predictions (Fig. 5) were low (10-30\%) over most of the AGDS data domain and increased to maximum values (50-60\%) for extreme and scattered roughness and hardness values. Chlorophyll- $a$ and pheophytin$a$ showed, respectively, the highest and the lowest predicted relative standard error distributions for the extent of the acoustic data.

Spatial distribution maps

The spatial distributions of the organic matter components predicted by the fitted GAMs were clearly related to the sediment classes established from the AGDS data. Highest values $(0.8-0.9 \%$ for TOC, $0.08-0.09 \%$ for $\mathrm{TN}, 2.6-3 \mu \mathrm{g} \mathrm{g}^{-1}$ for chlorophyll$a$ and $9-10 \mu \mathrm{g} \mathrm{g}^{-1}$ for pheophytin- $a$ ) corresponded with the very fine muddy sediment in the north of the study area (Fig. 6a, b, c, d, and Fig. 1, RoxAnn class 1). Mid-range concentrations $(0.5-0.6 \%$ for TOC, $0.05-0.07 \%$ for TN and $1.8-2.2 \mu \mathrm{g} \mathrm{g}^{-1}$ for Chl- $a$ ) were predicted over a different range of sediment types (Fig. 1a, RoxAnn class 3, 6, 7 and 8) including the south of the study area, corresponding with gravelly muddy sediment with pebbles, cobbles and boulders (Fig. 1, RoxAnn classes 8, 11 and 12). Pheo- $a$ differed from the other variables, showing high predicted concentrations in the gravelly muddy sediments. The lowest values for all response variables $(0.2-0.3 \%$ for TOC, $0.02-0.03 \%$ for TN, $0.6-1 \mu \mathrm{g} \mathrm{g}^{-1}$ for Chl- $a$ and 3-4 $\mu \mathrm{g} \mathrm{g}^{-1}$ for Pheo- $a$ ) were predicted in deepest areas, where the sediments were medium-coarse sands with pebbles (Fig. 1a, class 4), and in shallow areas dominated by fine sand (Fig. 1a, class 9 and 10). The highest relative standard errors were recorded (Fig. 6, $\mathrm{e}, \mathrm{f}, \mathrm{g}, \mathrm{h}$ ) in these sediments and also in the southwestern corner of the study area which contained areas of boulder and rock (Fig. 1, class 11 and 12).

In principal, the process of 'Kriging' the GAM predictions at each AGDS data location to the regular geographic grid introduced an additional source of error 


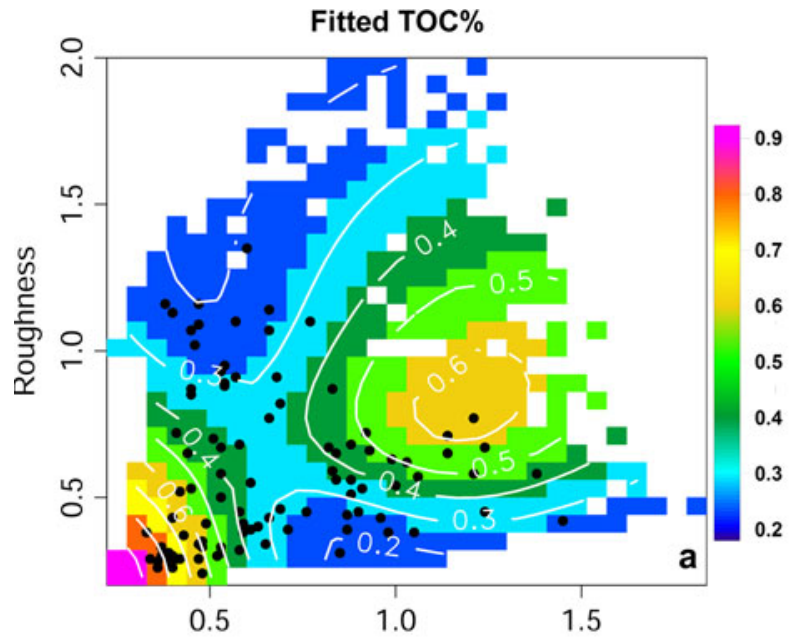

Fitted Chlorophyll-a $\left(\mu \mathrm{g} \mathrm{g}^{-1}\right)$ in May

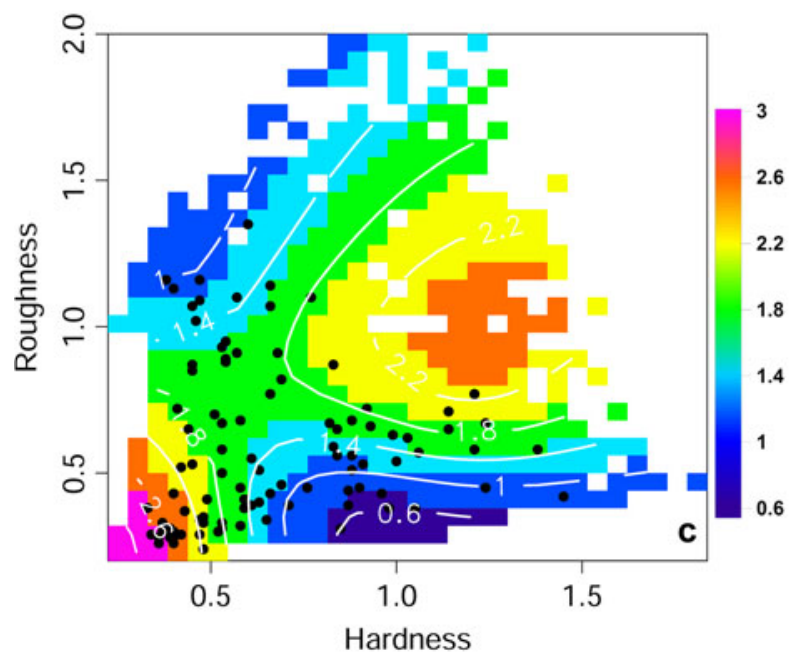

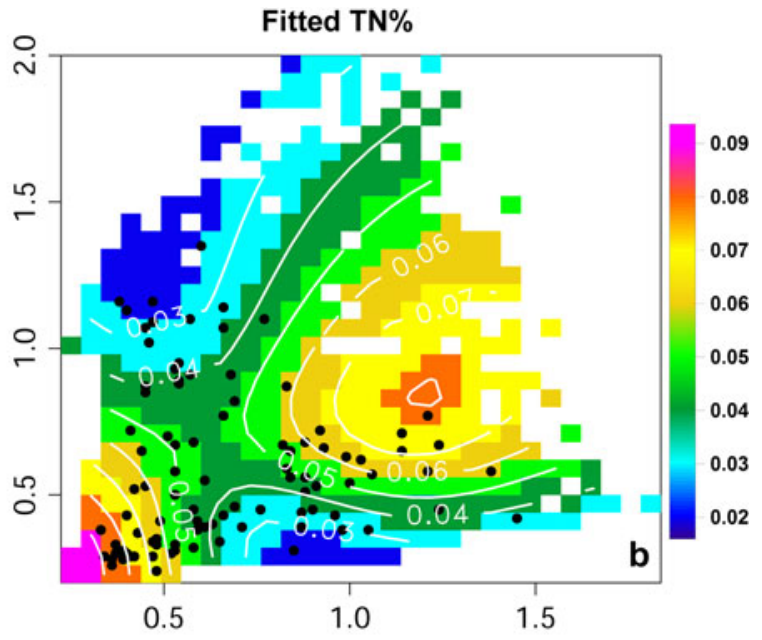

Fitted Pheophytin-a $\left(\mu \mathrm{g} \mathrm{g}^{-1}\right)$ in May

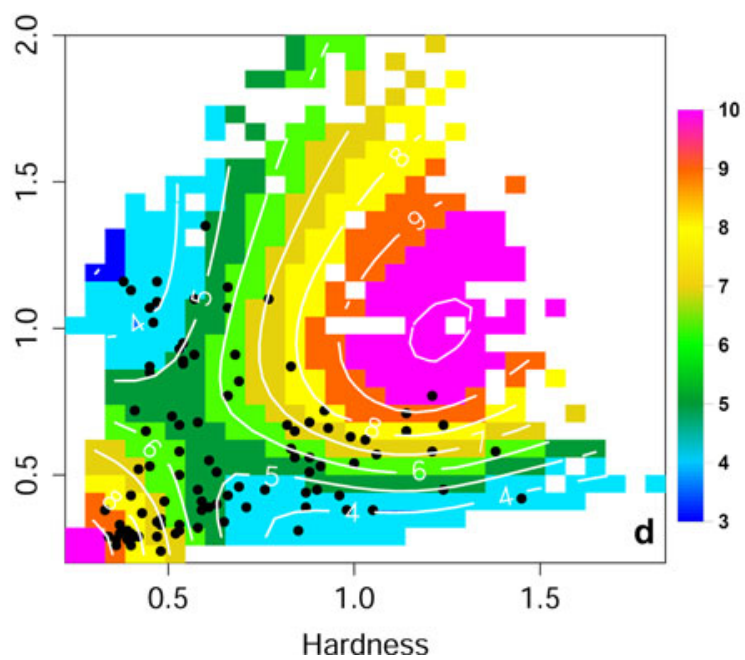

Fig. 3 Predicted TOC\% (a), TN\% (b), chlorophyll- $a$ (c) and pheophytin- $a$ (d) distributions for all the RoxAnn AGDS data points. Black dots represent the sediment sample values used to develop the model and the colour area is the foot-print of the acoustic data

in the maps of each variable. However, due to the very high data density, we estimated the relative standard error due to 'Kriging' to be between 0.6 and $2.8 \%$ for maximum and minimum values of TOC, respectively, as an example. Similarly, for the other response variables the contributions of 'Kriging' to the overall relative standard errors in the maps were insignificant compared to the standard error of the GAMs.

Spatial maps of directly interpolated grab sample TOC data

Spatial maps produced by direct 'Kriging' interpolation of the grab sample TOC data (Fig. 7a) showed a similar pattern to the map generated by the GAM model (Fig. 6a), identifying the highest concentrations in muddy sediments in the northern half of the study area, and medium in the mixed muddy, sandy, gravel sediments in the south. Standard errors of the gridded distributions were $\sim 10-20 \%$ over most of the survey area and increased exponentially to $100-200 \%$ in the centre area shallow waters (Fig. 7b).

\section{Discussion}

Conventional spatial interpolation based on point samples (Holtmann et al., 1996), and creating 

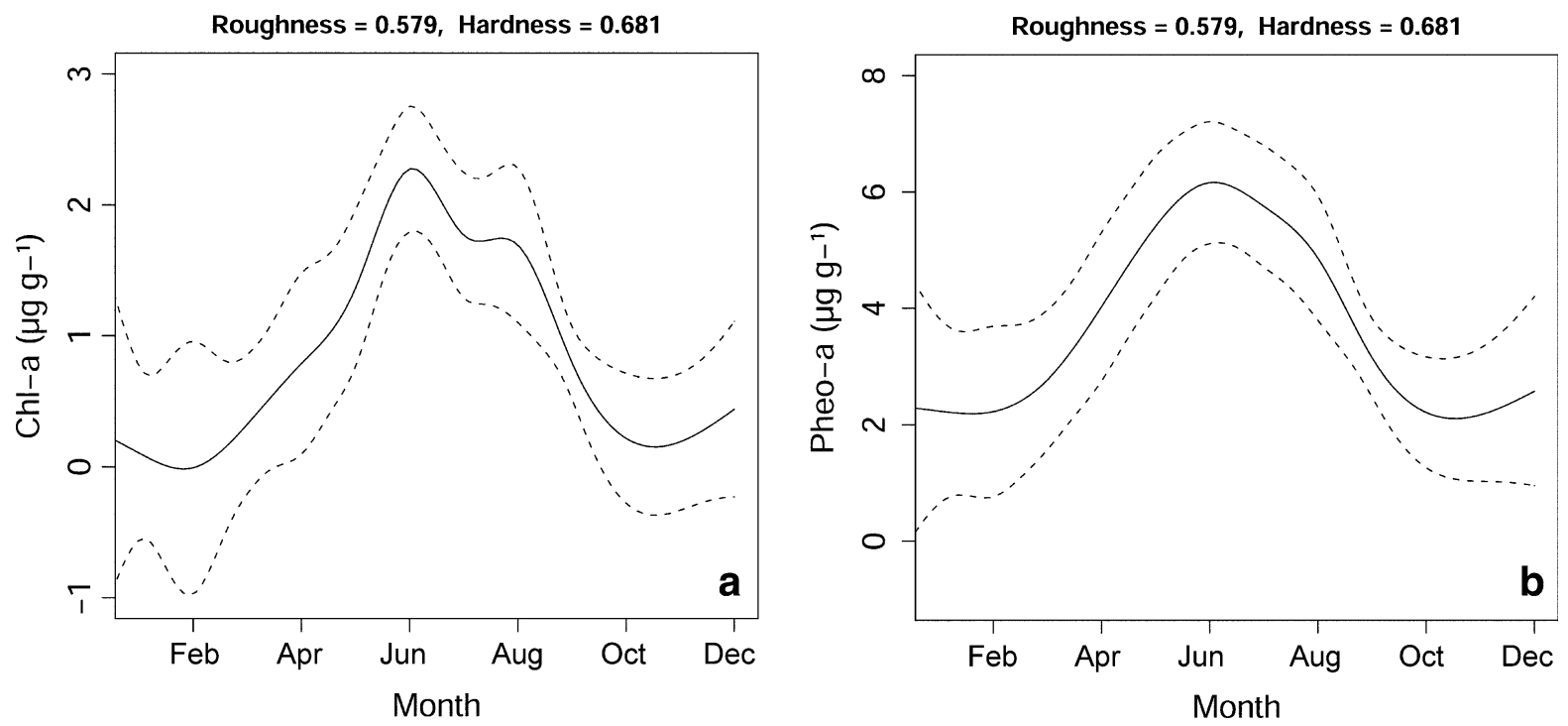

Fig. 4 Predicted chlorophyll- $a$ (a) and pheophytin- $a$ (b) (solid lines) \pm standard error (dotted lines) in different sampling months at mean values of roughness and hardness

statistical models to predict relationships between response and full coverage explanatory variables, are the two possible approaches which can be used to develop full coverage distribution maps of seabed properties. The second approach has been widely used to develop macrobenthos distribution maps linking habitat suitability models, based on biological data from points in different datasets and accompanying physical data (Shin, 1982; Guisan \& Zimmermann, 2000; Vanaverbeke et al., 2002; Caeiro et al., 2005; Degraer, 2008). Discriminant function analysis (DFA) is the validated statistical approach applied in these cases where the response variable is a categorical entity.

In this study, we used both direct interpolation and statistical modelling approaches to develop maps of the organic matter content of seabed sediments. The first approach, applied for TOC as an example, which involved 'Kriging' to interpolate point grab sample data onto a rectangular grid, produced smooth distribution maps (Fig. 7), which lacked the graininess of the full coverage maps derived by statistical modelling of the data relative to AGDS measurements (Fig. 6). The standard errors of the two approaches were similar over most of the study area but for the first approach also increased exponentially in areas lacking grab samples. The key issue in a comparison of the two approaches was therefore the extent to which the graininess of the full coverage maps was a genuine reflection of the spatial distribution of the response variables, or merely an artefact originating from the structure and variability of the underlying AGDS data.

Sediment organic matter content and acoustic properties

The relationships between organic matter content and AGDS properties of seabed sediments which emerge from our analysis arise principally because AGDS roughness and hardness are good predictors of mud content and median grain size, to which the organic components are closely related (McBreen et al., 2008). The 'plasticity' of GAMs that maximise the quality of prediction by estimating unspecific (non-parametric) functions of the predictor variables allow us to identify non-linear multi-dimensional relationships between response and explanatory variables. However, there are a number of factors which might complicate the relationship between organic matter and AGDS data.

Seabed sediments typically show detailed vertical structure, and the penetration of the AGDS acoustic beam into the sediment is difficult to evaluate. Penetration varies with the acoustic frequency and the grazing angle, with grain size, porosity and permeability of the receiving sediment, and also with different macrofauna communities (Chotiros et al., 


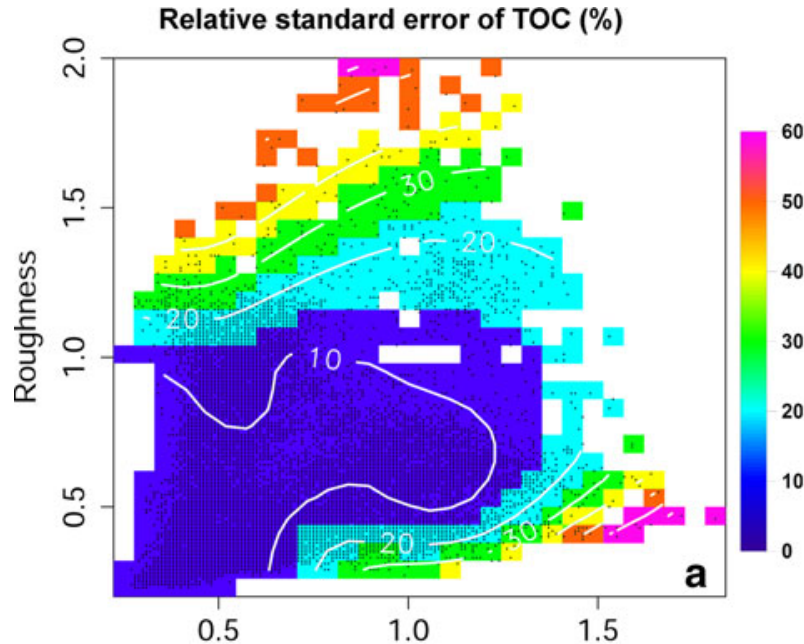

Relative standard error of Chlorophyll-a in May (\%)

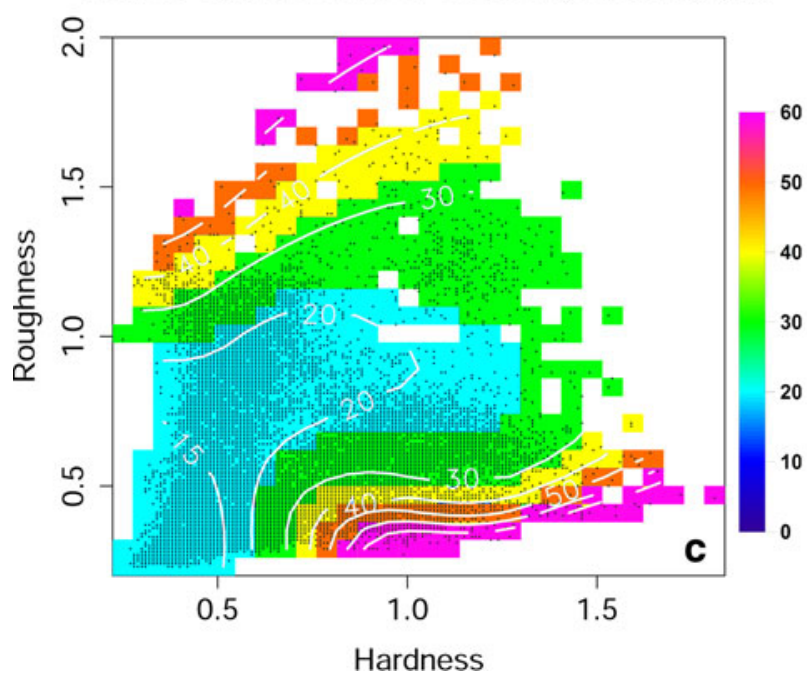

Fig. 5 Predicted relative standard error distributions (in \%) for TOC (a), TN (b), chlorophyll- $a$ (c) and pheophytin- $a$ (d) for all the RoxAnn data points. Black dots represent the acoustic values

1997). Hence, the depth interval over which we sampled organic matter could be critical. However, in the RoxAnn system, the initial part of the first returning echo that contains ambiguous sub-bottom reverberations is removed (Chivers et al., 1990), so that the derived indices of roughness and hardness refer predominantly to the upper few $\mathrm{cm}$ of sediment.

The length of sub-sample cores taken from the grab samples was nominally $5 \mathrm{~cm}$, but the penetration of the grab into the seabed was somewhat variable depending on sediment type and the ability of the survey vessel to maintain position during the sampling

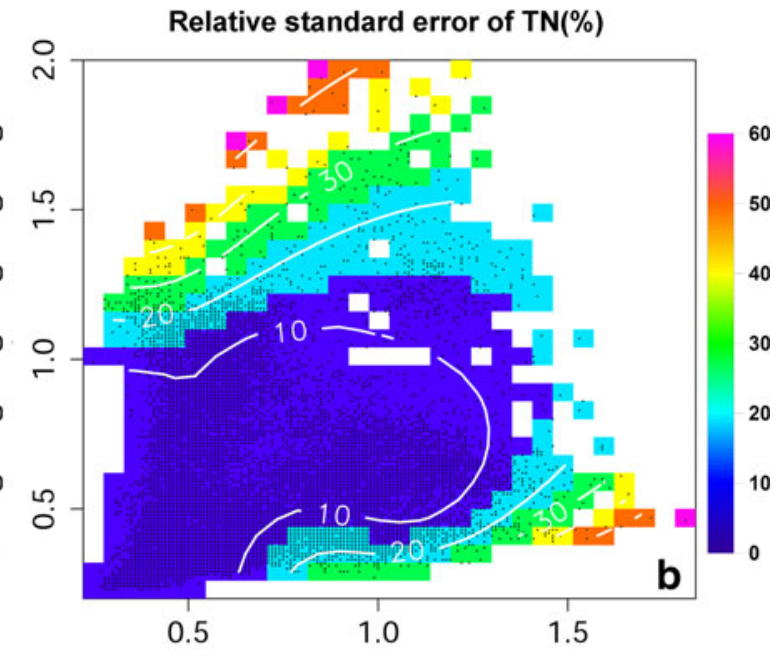

Relative standard error of Pheophytin-a in May (\%)

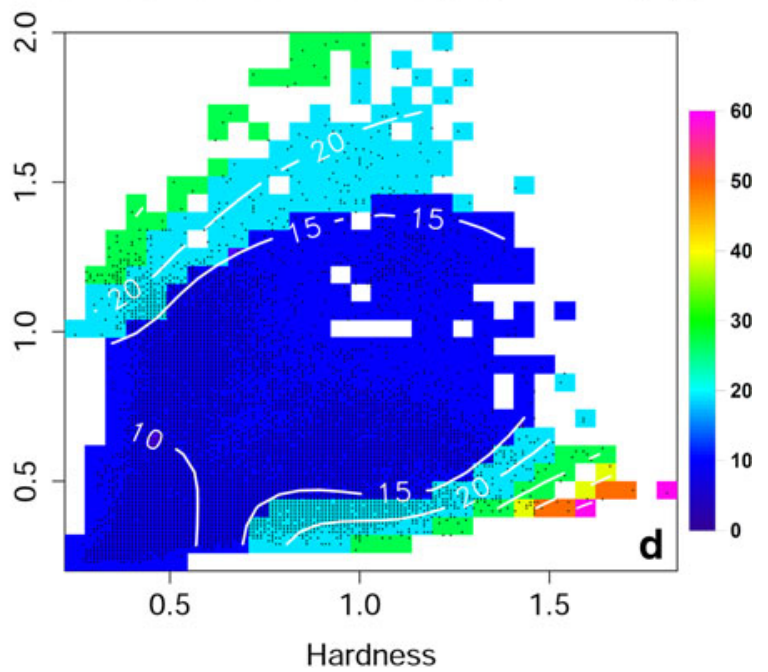

used for the model predictions and the colour area is the footprint of the acoustic data

operation. The core samples, on the other hand, were discretely sub-sampled at different depths. Because TOC and TN concentrations did not show seasonal variations and did not vary at different sediment depth we used measurements analysed in the top $1 \mathrm{~cm}$ (for these variables no significant differences were found between concentrations measured in the grab samples and the upper $1 \mathrm{~cm}$ of the core samples). However, pigments showed a strong seasonal variation, so for these response variables we used concentration measured in the top $0-5 \mathrm{~cm}$ of the cores to combine with the grab samples. 


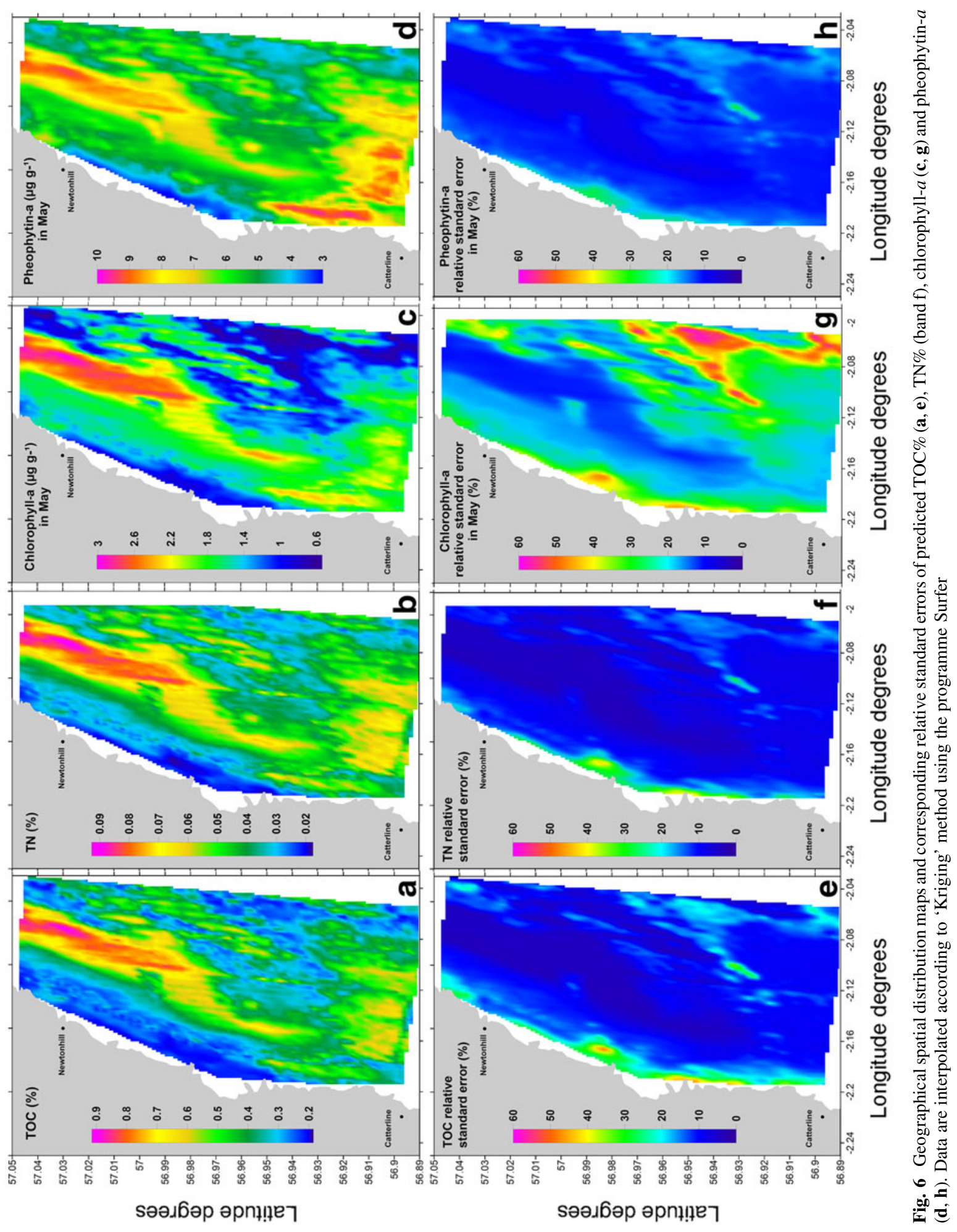


Fig. 7 Geographical spatial distribution map (a) and corresponding relative standard error (b) of TOC\% developed interpolating point grab samples. Data are interpolated according to

'Kriging' method; relative standard error map of the predictions were created exporting and converting the standard deviation of the 'Kriging' procedure created by the software Surfer

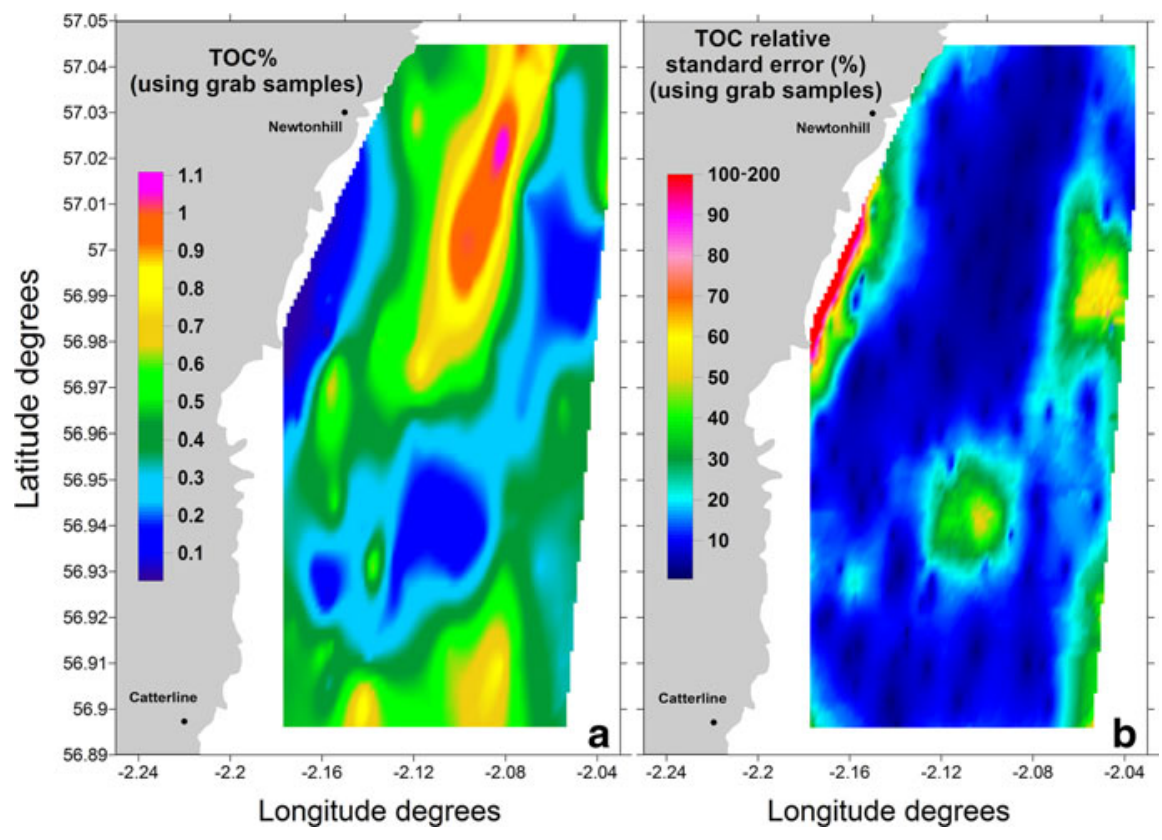

The seasonal patterns in our data were represented by the core sampling data which was focused on only seven sites, whilst the spatial patterns were represented by the grab sampling which covered $>100$ locations, but only on two occasions. Hence, we were unable to resolve interactions between space and time in our GAMs, and modelled time as an additive factor rather than a multiplicative factor. The consequence is that our GAMs predict the same relative seasonal pattern of variation in Chl- $a$ and Pheo- $a$ at all locations regardless of sediment type.

In our dataset, the relationship between organic matter and fine-grained sediment fractions (Winterwerp \& Van Kesteren, 2004; McBreen et al., 2008) was confirmed by the high correlation values of TOC and TN and Chl- $a$ and Pheo- $a$ with the percentage of mud (0.91, 0.9, 0.6 and 0.73, respectively, Table 1). However, the expected decrease of organic matter with increase of median grain size (Lohse et al., 1995; Janssen et al., 2005) did not extend to sediments with median grain size greater than $400 \mu \mathrm{m}$ (Fig. 2). This was due to poor sorting of the sediments and multimodal grain size distributions combining fine grain fractions with, for example, pebble and cobbles. Hence, high $(>10 \%)$ mud content, which is the main determinant of organic matter content, was often combined with high values of median grain size (stations 33, 38 and 39 in Table 3 and stations 24, 26, 27 and 29 in Table) (Fig. 2).
Hardness, as estimated by the AGDS, was highly correlated with the sediment grain size distributions (Serpetti et al., 2011). Roughness gave an indication of the topographical features of the sediment surface (e.g. ripples) which can influence the transport and sedimentation of organic matter (Jenness \& Duineveld, 1985; Janssen et al., 2005). In addition, roughness showed an extremely high negative Pearson correlation ( -0.9 , Table 1) with seabed depth: highest roughness values corresponding to shallow water sediments. In our study, the two variables are basically inter-changeable and the VIF analysis suggested which one to exclude. Considering the strong linear correlation between the two variables, roughness also represents the expected dependency of organic matter on depth (Jørgensen et al., 1990; Canfield et al., 1993; Wollast et al., 1998). The concurvity test, a generalisation of collinearity that can occur when using explanatory variables that can vary smoothly in space and/or time (Wood, 2003), also showed a strong collinearity between the smoothed covariates when depth was included as an explanatory variable; no concurvity was found after its removal.

Maps of predicted response variables

Our data confirmed that cohesive sediments are richer in organic matter than sandy sediments (Lohse et al., 1995; Janssen et al., 2005) with low percentage of mud 
Table 3 Sediment descriptors of grab samples collected during the ground truthing survey on April 2007

\begin{tabular}{|c|c|c|c|c|c|c|c|}
\hline Station & Longitude & Latitude & Description & $\begin{array}{l}\text { Median grain size } \\
(\mathrm{mm})\end{array}$ & $\begin{array}{l}\text { Mud content } \\
(\%)\end{array}$ & $\begin{array}{l}\text { TOC } \\
(\%)\end{array}$ & $\begin{array}{l}\mathrm{TN} \\
(\%)\end{array}$ \\
\hline 1 & -2.073 & 57.045 & Very fine muddy sand & 0.090 & 35.2 & 0.945 & 0.107 \\
\hline 2 & -2.141 & 56.938 & Medium sand & 0.376 & 4.0 & 0.228 & 0.043 \\
\hline 3 & -2.129 & 56.923 & Slightly gravelly coarse sand & 0.525 & 1.8 & 0.148 & 0.038 \\
\hline 4 & -2.138 & 56.931 & Gravelly medium muddy sand & 0.334 & 21.9 & 1.331 & 0.149 \\
\hline 5 & -2.158 & 56.970 & Slightly gravelly very fine muddy sand & 0.122 & 20.6 & 0.578 & 0.058 \\
\hline 6 & -2.116 & 56.953 & Slightly gravelly medium sand & 0.300 & 3.9 & 0.228 & 0.027 \\
\hline 7 & -2.169 & 56.921 & Medium muddy sand & 0.409 & 14.8 & 0.475 & 0.049 \\
\hline 8 & -2.088 & 56.962 & Medium sand & 0.300 & 4.6 & 0.36 & 0.051 \\
\hline 9 & -2.155 & 56.945 & Medium muddy sand & 0.256 & 10.9 & 0.418 & 0.431 \\
\hline 10 & -2.136 & 56.981 & Slightly gravelly very fine muddy sand & 0.120 & 23.2 & 0.616 & 0.057 \\
\hline 11 & -2.155 & 56.974 & Very fine muddy sand & 0.111 & 25.1 & 0.598 & 0.089 \\
\hline 12 & -2.111 & 57.018 & Fine muddy sand & 0.152 & 19.6 & 0.524 & 0.069 \\
\hline 13 & -2.143 & 56.926 & Gravelly coarse sand & 0.548 & 6.8 & 0.301 & 0.035 \\
\hline 14 & -2.059 & 57.036 & Slightly gravelly fine muddy sand & 0.240 & 10.8 & 0.439 & 0.051 \\
\hline 15 & -2.063 & 57.038 & Slightly gravelly fine muddy sand & 0.126 & 26.4 & 0.864 & 0.069 \\
\hline 16 & -2.046 & 57.026 & Slightly gravelly medium sand & 0.410 & 9.3 & 0.293 & 0.028 \\
\hline 17 & -2.090 & 56.938 & Gravelly coarse sand & 0.540 & 1.9 & 0.15 & 0.011 \\
\hline 18 & -2.091 & 57.009 & Very fine muddy sand & 0.082 & 37.3 & 0.901 & 0.069 \\
\hline 19 & -2.101 & 56.965 & Medium sand & 0.272 & 7.2 & 0.25 & 0.045 \\
\hline 20 & -2.082 & 57.006 & Very fine muddy sand & 0.102 & 33.1 & 0.909 & 0.113 \\
\hline 21 & -2.159 & 56.951 & Fine muddy sand & 0.152 & 15.2 & 0.460 & 0.049 \\
\hline 22 & -2.081 & 57.023 & Very fine muddy sand & 0.072 & 43.9 & 1.025 & 0.089 \\
\hline 23 & -2.094 & 56.993 & Very fine muddy sand & 0.080 & 40.8 & 1.021 & 0.122 \\
\hline 24 & -2.082 & 56.991 & Fine muddy sand & 0.175 & 19.9 & 0.615 & 0.045 \\
\hline 25 & -2.092 & 56.999 & Very fine muddy sand & 0.072 & 43.9 & 1.103 & 0.098 \\
\hline 26 & -2.098 & 56.986 & Very fine muddy sand & 0.091 & 36.0 & 0.912 & 0.092 \\
\hline 27 & -2.120 & 56.975 & Very fine muddy sand & 0.106 & 26.7 & 0.986 & 0.088 \\
\hline 28 & -2.176 & 56.948 & Fine muddy sand & 0.173 & 13.6 & 0.395 & 0.052 \\
\hline 29 & -2.171 & 56.962 & Fine sand & 0.204 & 5.5 & 0.237 & 0.04 \\
\hline 30 & -2.177 & 56.921 & NA & NA & NA & NA & NA \\
\hline 31 & -2.167 & 56.955 & Fine muddy sand & 0.151 & 16.1 & 0.432 & 0.057 \\
\hline 32 & -2.119 & 57.028 & Very fine muddy sand & 0.121 & 27.9 & 0.652 & 0.077 \\
\hline 33 & -2.157 & 56.905 & $\begin{array}{l}\text { Gravelly coarse muddy sand with pebbles and } \\
\text { cobbles }\end{array}$ & 0.811 & 11.0 & 0.268 & 0.062 \\
\hline 34 & -2.126 & 56.909 & $\begin{array}{l}\text { Gravelly coarse sand with pebbles and } \\
\text { cobbles }\end{array}$ & 0.986 & 4.8 & 0.299 & 0.032 \\
\hline 35 & -2.082 & 56.930 & Gravelly coarse muddy sand with cobbles & 0.519 & 15.2 & 0.469 & 0.074 \\
\hline 36 & -2.140 & 56.911 & Gravelly coarse sand & 0.688 & 3.3 & 0.226 & 0.027 \\
\hline 37 & -2.161 & 56.911 & $\begin{array}{l}\text { Gravelly very coarse muddy sand with } \\
\text { pebbles and cobbles }\end{array}$ & 0.589 & 11.7 & 0.479 & 0.062 \\
\hline 38 & -2.076 & 56.910 & Muddy gravel with pebbles and cobbles & 1.056 & 19.7 & 0.551 & 0.055 \\
\hline 39 & -2.083 & 56.911 & Muddy gravel with pebbles & 3.393 & 10.7 & 0.621 & 0.07 \\
\hline 40 & -2.056 & 56.966 & $\begin{array}{l}\text { Gravelly Fine muddy Sand with pebbles and } \\
\text { cobbles }\end{array}$ & 0.231 & 12.6 & 0.355 & 0.038 \\
\hline 41 & -2.139 & 56.996 & NA & NA & NA & NA & NA \\
\hline
\end{tabular}


Table 3 continued

\begin{tabular}{|c|c|c|c|c|c|c|c|}
\hline Station & Longitude & Latitude & Description & $\begin{array}{l}\text { Median grain size } \\
(\mathrm{mm})\end{array}$ & $\begin{array}{l}\text { Mud content } \\
(\%)\end{array}$ & $\begin{array}{l}\text { TOC } \\
(\%)\end{array}$ & $\begin{array}{l}\mathrm{TN} \\
(\%)\end{array}$ \\
\hline 42 & -2.179 & 56.932 & NA & NA & NA & NA & NA \\
\hline 43 & -2.158 & 56.989 & Coarse sand & 0.565 & 0.0 & 0.214 & 0.023 \\
\hline 44 & -2.125 & 56.925 & Slightly gravelly coarse sand & 0.556 & 2.1 & 0.207 & 0.019 \\
\hline 45 & -2.038 & 57.005 & Medium sand & 0.313 & 3.7 & 0.256 & 0.036 \\
\hline 46 & -2.124 & 56.928 & Slightly gravelly coarse sand & 0.574 & 1.3 & 0.126 & 0.018 \\
\hline 47 & -2.136 & 56.913 & Gravelly coarse sand & 0.804 & 2.3 & 0.187 & 0.044 \\
\hline 48 & -2.091 & 56.972 & Slightly gravelly fine muddy sand & 0.185 & 17.0 & 0.656 & 0.083 \\
\hline 49 & -2.110 & 56.995 & $\begin{array}{l}\text { Gravelly very fine muddy sand with pebbles } \\
\text { and cobbles }\end{array}$ & 0.090 & 33.9 & 0.726 & 0.073 \\
\hline 50 & -2.130 & 56.960 & Slightly gravelly fine muddy sand & 0.238 & 11.8 & 0.516 & 0.071 \\
\hline
\end{tabular}

The term "NA" indicates the stations where the grab failed and the underlined numbers indicate concentrations below the detection limit

content (Winterwerp \& Van Kesteren, 2004). Hence, the spatial distributions of chemical properties showed that the area of very fine muddy sediment in the north of the study area (Fig. 1, class 1 ) is a depositional area where organic matter is accumulating. Lowest values of organic matter were predicted for well-sorted, shallow water fine sand and smooth medium-coarse sand and boulders in deep waters. However, relatively high concentrations of TOC, TN, Chl- $a$ and especially Pheo- $a$ were also predicted for hard sediment in the south of the area, characterised by poorly sorted gravelly muddy sand with pebbles and cobbles. Percentages of mud greater than $10 \%$ recorded in this area (Table 3, stations 33, 38 and 39, and Table 4, stations 24, 26, 27 and 29) were presumably responsible for this distribution. In the case of Pheo- $a$, the high concentration predicted in this area could reflect a high degradation rate of pigment in this type of sediment. Chlorophyll is degraded relatively fast compared to pheophytin by the removal of the $\mathrm{Mg}$ atom from the tetrapyrole ring. More than $95 \%$ of the pigment degradation happens very rapidly in the water (half-life of days) (Patoine \& Leavitt, 2006). In the sediment, the decay of pigments is generally less rapid (Leavitt, 1993) and Chl- $a$, as a labile carbon source, can be used to trace the early diagenesis of organic matter in lakes and coastal marine sediments (Furlong \& Carpenter, 1988; Sun et al., 1991, 1993; Stephens et al., 1997). The degradation of chlorophyll to pheophytin is influenced by a range of factors such as oxygen availability, exposure to light and microbial and macrofauna abundance (Stephens et al., 1997;
Bianchi et al., 2000). Under oxic conditions, which are generally present in gravelly medium-coarse sands (Janssen et al., 2005), the chlorophyll decay rates are higher than in cohesive anoxic sediment (Boon \& Duineveld, 1998; Bianchi et al., 2000). This explains the high concentration of Chl- $a$ (Fig. 6c) in very fine muddy substrates and, due to the refractory property of pheophytin in the sediment (Stephens et al., 1997; Patoine \& Leavitt, 2006), the high Pheo- $a$ concentration (Fig. 6d) in gravelly coarse muddy sediments.

Low concentrations for all response variables were predicted in the shallow inshore waters (Fig. 6c, d). Shallow coastal waters are usually zones of high productivity and turbulence where nutrients are mixed into the water column (Jenness \& Duineveld, 1985), but sediments are frequently re-suspended by wave action and tides. Phyto-detritus is less likely to settle in such conditions and is presumably transported to less turbulent areas to settle instead (Creutzberg et al., 1984). The very fine muddy sands, located in deeper waters, represent the depositional and accumulation area for fine-grained particles and organic matter formed or carried into the study area.

Spatial distributions of high relative standard error indicated where the model did not fit with the observed data. There are different factors that could result in high values of error. Relative standard errors for the response variables (Fig. 5) were higher at the extremes of roughness and hardness range where both the acoustic and grab sampling data were sparse. These areas are shown by the black points in Figs. 3 and 5 
Table 4 Sediment descriptors of grab samples collected during the second ground truthing survey on September 2008

\begin{tabular}{|c|c|c|c|c|c|c|c|c|c|}
\hline Station & Longitude & Latitude & Description & $\begin{array}{l}\text { Median } \\
\text { grain size } \\
(\mathrm{mm})\end{array}$ & $\begin{array}{l}\text { Mud } \\
\text { content } \\
(\%)\end{array}$ & $\begin{array}{l}\text { TOC } \\
(\%)\end{array}$ & $\begin{array}{l}\mathrm{TN} \\
(\%)\end{array}$ & $\begin{array}{l}\text { Chl- } a \\
\left(\mu g g^{-1}\right)\end{array}$ & $\begin{array}{l}\text { Pheo- } a \\
\left(\mu \mathrm{g} \mathrm{g}^{-1}\right)\end{array}$ \\
\hline 1 & -2.096 & 56.993 & Very fine muddy sand & 0.083 & 37.3 & 0.95 & 0.092 & 1.961 & 5.230 \\
\hline 2 & -2.087 & 57.020 & Very fine muddy sand & 0.080 & 38.2 & 1 & 0.11 & 1.626 & 4.886 \\
\hline 3 & -2.073 & 57.037 & Very fine muddy sand & 0.099 & 28.7 & 0.8 & 0.082 & 1.290 & 4.219 \\
\hline 4 & -2.146 & 56.946 & Medium sand & 0.270 & 8 & 0.26 & 0.031 & 0.753 & 2.275 \\
\hline 5 & -2.073 & 56.965 & Medium sand & 0.256 & 5.9 & 0.21 & 0.027 & 1.125 & 0.402 \\
\hline 6 & -2.118 & 56.973 & Very fine muddy sand & 0.106 & 26.6 & 0.81 & 0.086 & 1.742 & 4.145 \\
\hline 7 & -2.086 & 56.988 & Fine muddy sand & 0.142 & 22.3 & 0.65 & 0.076 & 1.232 & 3.920 \\
\hline 8 & -2.066 & 57.026 & Fine muddy sand & 0.154 & 20.6 & 0.63 & 0.069 & 0.755 & 3.456 \\
\hline 9 & -2.048 & 57.008 & Fine sand & 0.240 & 5.5 & 0.25 & 0.023 & 0.237 & 2.081 \\
\hline 10 & -2.128 & 56.932 & Gravelly medium sand & 0.334 & 3.3 & 0.11 & 0.031 & 0.344 & 0.815 \\
\hline 12 & -2.084 & 56.978 & $\begin{array}{l}\text { Slightly gravelly fine muddy } \\
\text { sand }\end{array}$ & 0.198 & 12.9 & 0.34 & 0.04 & 1.032 & 3.341 \\
\hline 13 & -2.071 & 57.011 & Fine muddy sand & 0.217 & 13.8 & 0.2 & 0.027 & 0.740 & 2.393 \\
\hline 14 & -2.036 & 57.012 & Medium sand & 0.251 & 6 & 0.67 & 0.087 & 0.602 & 1.958 \\
\hline 15 & -2.052 & 57.035 & Gravelly fine muddy sand & 0.196 & 19.6 & 0.26 & 0.041 & 1.290 & 5.662 \\
\hline 16 & -2.074 & 56.901 & Gravelly medium sand & 0.314 & 9.0 & 0.5 & 0.045 & 0.688 & 1.517 \\
\hline 17 & -2.077 & 56.940 & Gravelly medium muddy sand & 0.344 & 10.4 & 0.35 & 0.036 & 0.740 & 2.879 \\
\hline 18 & -2.052 & 56.944 & Gravelly medium sand & 0.278 & 8.8 & 0.35 & 0.042 & 0.473 & 3.302 \\
\hline 19 & -2.164 & 56.930 & Medium sand & 0.337 & 4.1 & 0.15 & 0.019 & 0.331 & 1.306 \\
\hline 20 & -2.138 & 56.983 & Fine muddy sand & 0.130 & 14.3 & 0.41 & 0.05 & 1.118 & 4.339 \\
\hline 21 & -2.093 & 57.036 & Fine muddy sand & 0.157 & 18 & 0.5 & 0.059 & 1.118 & 4.003 \\
\hline 22 & -2.082 & 56.909 & Gravelly medium muddy sand & 0.257 & 25.7 & 0.81 & 0.1 & 0.839 & 6.226 \\
\hline 23 & -2.100 & 56.909 & NA & NA & NA & NA & NA & NA & NA \\
\hline 24 & -2.142 & 56.902 & $\begin{array}{l}\text { Gravelly very coarse muddy } \\
\text { sand with pebbles and cobbles }\end{array}$ & 1.984 & 21.5 & 0.88 & 0.11 & 1.484 & 7.543 \\
\hline 25 & -2.135 & 56.917 & Gravelly medium muddy sand & 0.392 & 10 & 0.22 & 0.036 & 0.396 & 2.527 \\
\hline 26 & -2.140 & 56.896 & $\begin{array}{l}\text { Gravelly very coarse muddy } \\
\text { Sand with pebbles and cobbles }\end{array}$ & 1.677 & 13.1 & 0.68 & 0.088 & 0.559 & 3.291 \\
\hline 27 & -2.113 & 56.901 & $\begin{array}{l}\text { Gravelly coarse muddy sand } \\
\text { with pebbles and cobbles }\end{array}$ & 0.978 & 13.3 & 0.5 & 0.066 & 1.124 & 5.189 \\
\hline 28 & -2.156 & 56.913 & Gravelly medium muddy sand & 0.442 & 13.2 & 0.5 & 0.071 & 0.419 & 2.454 \\
\hline 29 & -2.105 & 56.913 & $\begin{array}{l}\text { Gravelly muddy granule with } \\
\text { pebbles and cobbles }\end{array}$ & 2.591 & 10.3 & 0.61 & 0.067 & 0.750 & 4.265 \\
\hline 30 & -2.173 & 56.962 & Fine sand & 0.200 & 8.7 & 0.23 & 0.028 & 1.147 & 2.916 \\
\hline 31 & -2.155 & 56.993 & Medium sand & 0.267 & 4.7 & 0.11 & 0.015 & 0.419 & 1.557 \\
\hline 32 & -2.121 & 57.014 & Fine muddy sand & 0.147 & 18 & 0.47 & 0.052 & 2.249 & 4.504 \\
\hline 33 & -2.172 & 56.919 & Gravelly medium muddy sand & 0.282 & 15 & 0.46 & 0.061 & 1.521 & 7.372 \\
\hline 34 & -2.129 & 57.013 & Fine muddy sand & 0.169 & 15.6 & 0.33 & 0.043 & 2.315 & 5.151 \\
\hline 35 & -2.114 & 57.038 & Fine muddy sand & 0.155 & 18 & 0.44 & 0.051 & 1.896 & 3.338 \\
\hline 36 & -2.146 & 57.019 & Fine sand & 0.206 & 0 & 0.096 & 0.013 & 0.485 & 1.400 \\
\hline 37 & -2.150 & 57.009 & Fine sand & 0.210 & 2.4 & 0.092 & 0.013 & 0.536 & 1.270 \\
\hline 38 & -2.169 & 56.984 & Medium sand & 0.330 & 1.4 & 0.044 & 0.01 & 0.112 & 0.318 \\
\hline 39 & -2.177 & 56.974 & Medium sand & 0.252 & 0 & 0.026 & 0.0064 & 0.172 & 0.653 \\
\hline
\end{tabular}


Table 4 continued

\begin{tabular}{|c|c|c|c|c|c|c|c|c|c|}
\hline Station & Longitude & Latitude & Description & $\begin{array}{l}\text { Median } \\
\text { grain size } \\
(\mathrm{mm})\end{array}$ & $\begin{array}{l}\text { Mud } \\
\text { content } \\
(\%)\end{array}$ & $\begin{array}{l}\text { TOC } \\
(\%)\end{array}$ & $\begin{array}{l}\mathrm{TN} \\
(\%)\end{array}$ & $\begin{array}{l}\text { Chl- } a \\
\left(\mu \mathrm{g} \mathrm{g}^{-1}\right)\end{array}$ & $\begin{array}{l}\text { Pheo- } a \\
\left(\mu g^{-1}\right)\end{array}$ \\
\hline 40 & -2.183 & 56.945 & NA & NA & NA & NA & NA & NA & NA \\
\hline 41 & -2.187 & 56.925 & NA & NA & NA & NA & NA & NA & NA \\
\hline 42 & -2.184 & 56.912 & NA & NA & NA & NA & NA & NA & NA \\
\hline 43 & -2.158 & 56.981 & Coarse sand & 0.820 & 4.8 & 0.027 & 0.0058 & 0.298 & 0.950 \\
\hline 44 & -2.046 & 56.983 & Slightly gravelly medium sand & 0.263 & 5.7 & 0.16 & 0.022 & 0.265 & 2.975 \\
\hline 45 & -2.066 & 56.931 & Gravelly medium muddy sand & 0.272 & 16.2 & 0.3 & 0.043 & 0.335 & 2.984 \\
\hline 46 & -2.101 & 56.931 & Gravelly medium sand & 0.386 & 4.9 & 0.12 & 0.02 & 0.265 & 1.547 \\
\hline 47 & -2.149 & 56.950 & Medium sand & 0.276 & 9.7 & 0.34 & 0.043 & 1.279 & 3.369 \\
\hline 48 & -2.146 & 56.973 & Fine muddy sand & 0.126 & 16.8 & 0.41 & 0.052 & 2.580 & 4.173 \\
\hline A & -2.088 & 57.016 & Very fine muddy Sand & 0.081 & 38.1 & 0.97 & 0.097 & 1.741 & 6.944 \\
\hline $\mathrm{B}$ & -2.121 & 56.980 & Very fine muddy Sand & 0.105 & 28.1 & 0.68 & 0.08 & 2.410 & 7.338 \\
\hline $\mathrm{C}$ & -2.116 & 57.005 & Fine muddy sand & 0.135 & 22.2 & 0.51 & 0.061 & 1.805 & 5.262 \\
\hline $\mathrm{D}$ & -2.171 & 56.963 & Fine sand & 0.216 & 6.3 & 0.18 & 0.021 & 0.803 & 2.484 \\
\hline $\mathrm{E}$ & -2.079 & 56.946 & Gravelly medium muddy sand & 0.312 & 15.2 & 0.4 & 0.046 & 0.562 & 4.516 \\
\hline $\mathrm{F}$ & -2.121 & 56.960 & Medium sand & 0.313 & 6.7 & 0.2 & 0.02 & 0.573 & 2.351 \\
\hline $\mathrm{G}$ & -2.158 & 56.924 & Medium sand & 0.384 & 0.6 & 0.067 & 0.012 & 0.218 & 0.656 \\
\hline
\end{tabular}

The term "NA" indicates the stations where the grab failed, and the underlined number indicates concentration below the detection limit

that illustrated grab samples and acoustic data densities in the RoxAnn space. In particular, we have low confidence in the predictions for sediments in the south-western corner of the study area (Fig. 1, classes 11 and 12) where we were unable to collect grab samples: five planned grab sampling stations, located in this area, failed (stations 30 and 42 in Table 3 and 40, 41 and 42 in Table 4): the video recorded during the ground truthing surveys showed small patches of muddy sediments in between boulders and attached Alcyonarian species Alcyonium digitatum (for video details see Table 3 in Serpetti et al., 2011). These sediments correspond to a range of roughness and hardness values above 1 (Fig. 3). High relative standard errors were also predicted very close to the shore in the shallowest sediments in the centre of the study area: potential inputs of terrestrial organic matter (land runoff and riverine inputs), could explain this error. The remineralisation of refractory terrestrial organic matter in the marine environment is less efficient than that of marine organic matter (Burdige, 2005), so further validations are required to asses the terrestrial contribution to the organic matter content of the shallow inshore waters (e.g. carbon and nitrogen isotope signatures).

Comparing the predicted values of the response variables and their relative standard errors in the RoxAnn space (Figs. 3, 5) with the corresponding spatial distribution maps (Fig. 6) it is evident that the extrapolations of predicted values for high roughness and hardness areas, where both grab samples and acoustic data were sparse, represented a small geographical part of the whole study area. Hence, high predicted relative standard errors (greater than 30\%) actually affect only a small number of locations.

The time dependency of the Chl- $a$ and Pheo- $a$ (Fig. 4) showed that these parameters of the organic content of the sediment are not stationary, or circular, since there was no exact correspondence between predicted concentrations at the start and end of the time series. This underlined the differences between the 2 years in which the study was carried out: the Chl- $a$ and Pheo- $a$ concentrations measured in June 2008 were higher than in June 2009 (Serpetti et al., in preparation). However, these high concentrations reflected the seasonal patterns of this pigment in the 
water column indicating that the phyto-detritus in the sediment in June-08 was of very recent origin: hence we can not assume that the overall seasonal patterns are constant between years (Serpetti et al., in preparation).

The keys of the mapping method developed in this article are the well known relationships between the RoxAnn properties roughness and hardness with sediment features and grain size distribution (Hamilton et al., 1999; Foster-Smith et al., 2004; Serpetti et al., 2011) and between these sediment physical properties and organic matter contents (Winterwerp \& Van Kesteren, 2004; Janssen et al., 2005; McBreen et al., 2008). For this reason, this approach could be potentially extended and applied to other study areas supplying high resolution maps of organic matter and/or sediment characteristics in coastal waters. Moreover, the flexibility of the statistical method allows adding other potential factors to improve the model performance. For example, water depth and distance from the coast line, which in our case were not significant, could affect the distribution of organic matter and the sediment physical characteristics in other study areas.

\section{Conclusion}

In-depth sediment biogeochemistry investigations are only possible at a limited number of discrete stations: modelling and mapping tools allow us to upscale the results to a wide study area. By means of GAM modelling, we have been able to extend the utility of AGDS data to mapping spatial distributions of organic carbon, nitrogen, Chl- $a$ and pheophytin- $a$ identifying the factors that can influence them.

Acknowledgements This work was co-funded by the Marine Scotland-Science Laboratory Aberdeen, and University of Aberdeen, through the joint Fisheries Research Fund. In addition, the authors acknowledge the support of the MASTS pooling initiative (The Marine Alliance for Science and Technology for Scotland) in the completion of this study. MASTS is funded by the Scottish Funding Council (grant reference HR09011) and contributing institutions. Our thanks to the captains and crews of the research vessels Scotia, Clupea, Alba na Mara and Temora, and to our colleagues who have assisted with various aspects of the work at sea and in the laboratory, especially John Dunn, Steve Hay, Eric Armstrong, Phil Copland, Pete Hayes, Jane Heron, Colin Megginson,
Charlie Shand and Paul Stainer. Thanks also to Doug Webster for help with the graphics and for his constant support.

\section{References}

Arar, E. J. \& G. B. Collins, 1997. In vitro Determination of Chlorophyll a and Pheophytin a in Marine and Freshwater Algae by Fluorescence, Method 445.0. National Exposure Research Laboratory, Office of Research and Development, U.S., Environmental Protection Agency, Cincinnati, $\mathrm{OH}$.

Baxter, J. M., I. L. Boyd, M. Cox, L. Cunningham, P. Holmes \& C. F. Moffat, 2008. Scotland's seas: Towards Understanding their State. Chapter 2. Physical Characteristics and Modelling of the Marine Environment (Case Study 2.2 Seabed sediments). Fisheries Research Services, Aberdeen: $28 \mathrm{pp}$ [availble on internet at http://www.scotland.gov. uk/Resource/Doc/218570/0058690.pdf].

Bianchi, T. S., B. Johansson \& R. Elmgren, 2000. Breakdown of phytoplankton pigments in Baltic sediments: effects of anoxia and loss of deposit-feeding macrofauna. Journal of Experimental Marine Biology and Ecology 251: 161-183.

Burdige, D. J., 2005. Burial of terrestrial organic matter in marine sediments: a re-assessment. Global Biogeochemical Cycles 19: GB4011.

Boon, A. R. \& G. C. A. Duineveld, 1998. Chlorophyll a as a marker for bioturbation and carbon flux in southern and central North Sea sediments. Marine Ecology Progress Series 162: 33-43.

Caeiro, S., M. H. Costa, P. Goovaerts \& F. Martins, 2005. Benthic biotope index for classifying habitats in the Sado estuary: Portugal. Marine Environmental Research 60: 570-593.

Calvert, S. E., 1987. Oceanographic controls on the accumulation of organic matter in marine sediments. Geological Society, London, Special Publications 26: 137-151.

Canfield, D. E., R. Wollast, F. T. Mackenzie \& L. Chou, 1993. Organic matter oxidation in marine sediments. In Wollast, R., F. T. Mackenzie \& L. Chou (eds), Interactions of C, N, $\mathrm{P}$ and $\mathrm{S}$ Biogeochemical Cycles and Global Change. Springer, Berlin: 333-363.

Cawley, G. C. \& N. L. C. Talbot, 2010. On over-fitting in model selection and subsequent selection bias in performance evaluation. Journal of Machine Learning Research 11: 2079-2107.

Chivers, R. C., N. C. Emerson \& D. Burns, 1990. New acoustic processing for underway surveying. The Hydrographic Journal 56: 9-17.

Chotiros, N. P., A. M. Mautner, A. Løvik, A. Kristensen \& O. Bergem, 1997. Acoustic penetration of a silty sand sediment in the $1-10-\mathrm{kHz}$ band. IEEE Journal of Oceanic Engineering 22(4): 604-615.

Conley, D. J. \& R. W. Johnstone, 1995. Biogeochemistry of N, P and $\mathrm{Si}$ in Baltic Sea sediments: response to a simulated deposition of a spring bloom. Marine Ecology Progress Series 122: 265-276. 
Creutzberg, F., P. Wapenaar, G. Duineveld \& N. Lopez, 1984. Distribution and density of the benthic fauna in the southern North Sea in relation to bottom characteristics and hydrographic conditions. Journal du Conseil International pour l'exploration de la Mer 183: 101-110.

Degraer, S., E. Verfaillie, W. Willems, E. Adriaens, M. Vincx \& V. Van Lancker, 2008. Habitat suitability modelling as a mapping tool for macrobenthic communities: an example from the Belgian part of the North Sea. Continental Shelf Research 28: 369-379.

Ehrenhauss, S., U. Witte, F. Janssen \& M. Huettel, 2004. Decomposition of diatoms and nutrient dynamics in permeable North Sea sediments. Continental Shelf Research 24: 721-737.

Folk, R. L., 1954. The distinction between grain size and mineral composition in sedimentary rock nomenclature. Journal of Geology 62(4): 344-359.

Furlong, E. T. \& R. Carpenter, 1988. Pigment preservation and remineralization in oxic coastal marine sediments. Geochimica et Cosmochimica Acta 52: 87-99.

Foster-Smith, R. L., C. J. Brown, W. J. Meadows, W. White \& D. S. Limpenny, 2004. Mapping seabed biotopes at two spatial scales in the Eastern English Channel. Part 2: comparison of two acoustic ground discrimination systems. Journal of the Marine Biological Association of the United Kingdom 84: 489-500.

Guisan, A. \& N. E. Zimmermann, 2000. Predictive habitat distribution models in ecology. Ecological Modelling 135: 147-186.

Hamilton, L. J., P. J. Mulhearn \& R. Poeckert, 1999. Comparison of RoxAnn and QTC-View acoustic bottom classification system performance for the Cairns area, Great Barrier Reef, Australia. Continental Shelf Research 19: 1577-1597.

Holtmann, S. E., A. Groenewold, K. H. M. Schrader, J. Asjes, J. A. Craeymeersch, G. C. A. Duineveld, A. J. van Bostelen \& J. Van Der Meer, 1996. Atlas of the Zoobenthos of the Dutch Continental Shelf. Ministry of Transport, Public Works and Water Management, Rijswijk, The Netherlands. ISBN 90-369-4301-9.

ICES, 2005. Report of the Working Group on Marine Habitat Mapping (WGMHM), Bremerhaven, Germany, 5-8 April, ICES CM 2005/E:05: 85 pp, unpublished.

Janssen, F., M. Huettel \& U. Witte, 2005. Pore-water advection and solute fluxes in permeable marine sediment (II): benthic respiration at three sandy sites with different permeabilities (German Bight, North Sea). Limnology and Oceanography 50(3): 779-792.

Jenness, M. I. \& G. C. A. Duineveld, 1985. Effects of tidal currents on chlorophyll a content of sandy sediments in the southern North Sea. Marine Ecology Progress Series 21: 283-287.

Jørgensen, B. B., M. Bang \& T. H. Blackburn, 1990. Anaerobic mineralization in marine sediments from the Baltic SeaNorth Sea transition. Marine Ecology Progress Series 59: $39-54$.

Leavitt, P. R., 1993. A review of factors that regulate carotenoid and chlorophyll deposition and fossil pigment abundance. Journal of Paleolimnology 9: 109-127.

Lohse, L., J. F. P. Malschaert, C. P. Slomp, W. Helder \& W. van Raaphorst, 1995. Sediment-water fluxes of inorganic nitrogen compounds along the transport route of organic matter in the North Sea. Ophelia 41: 173-197.

Lorenzen, C. J., 1967. Determination of chlorophyll and pheopigments: spectroscopic equations. Limnology and Oceanography 12: 343-346.

McBreen, F., J. G. Wilson, A. S. Y. Mackie \& C. N. Aonghusa, 2008. Seabed mapping in the southern Irish Sea: predicting benthic biological communities based on sediment characteristics. Hydrobiologia 606: 93-103.

Montgomery, D. C. \& E. A. Peck, 1992. Introduction to Linear Regression Analysis. Wiley, New York.

Ogrinc, N., G. Fontolan, J. Faganeli \& S. Covelli, 2005. Carbon and nitrogen isotope compositions of organic matter in coastal marine sediments (the Gulf of Trieste, $\mathrm{N}$ Adriatic Sea): indicators of sources and preservation. Marine Chemistry 95: 163-181.

Patoine, A. \& P. R. Leavitt, 2006. Century-long synchrony of fossil algae in a chain of Canadian prairie lakes. Ecology 87: $1710-1721$.

Rutgers Van Der Loeff, M. M., 1980. Nutrients in the interstitial waters of the Southern Bight of the North Sea. Netherland of Journal of Sea Research 14: 144-171.

Serpetti, N., M. R. Heath, E. Armstrong \& U. Witte, 2011. Blending single beam RoxAnn and multi-beam swathe QTC hydro-acoustic discrimination techniques for the Stonehaven area, Scotland, UK. Journal of Sea Research 65: 442-455.

Serpetti, N., M. R. Heath \& U. Witte, in preparation. Modelling the main drivers of spatial and temporal variability in sediment metabolism and nutrient fluxes off the north-east coast of Scotland, UK.

Shin, P. K. S., 1982. Multiple discriminant analysis of macrobenthic infaunal assemblages. Journal of Experimental Marine Biology and Ecology 59: 39-50.

Stephens, M. P., D. C. Kadko, C. R. Smith \& M. Latasa, 1997. Chlorophyll-a and pheopigments as tracers of labile organic carbon at the central equatorial Pacific seafloor. Geochimica et Cosmochimica Acta 61(21): 4605-4619.

Strickland, J. D. H. \& T. R. Parsons, 1972. A practical handbook of seawater analysis. Fisheries Research Board of Canada Bulletin 167: $311 \mathrm{pp}$.

Sun, M.-Y., R. C. Aller \& C. Lee, 1991. Early diagenesis of chlorophyll-a in Long Island Sound sediments: a measure of carbon flux and particle reworking. Journal of Marine Research 49: 379-401.

Sun, M.-Y., C. Lee \& R. C. Aller, 1993. Anoxic and oxic degradation of ${ }^{14} \mathrm{C}$-labelled chloropigments and a ${ }^{14} \mathrm{C}$-labelled diatom in Long Island Sound sediments. Limnology and Oceanography 38: 1438-1451.

ThermoQuest FlashEA 1112 Elemental Analyser Operating Manual, 1999. Part Number 317, 08241, 2nd ed, November 1999.

Udden, J. A., 1914. Mechanical composition of clastic sediments. Geological Society of America Bulletin 25: 655-744.

Vanaverbeke, J., T. Gheskiere, M. Steyaert \& M. Vincx, 2002. Nematode assemblages from subtidal sandbanks in the Southern Bight of the North Sea: effect of small sedimentological differences. Journal of Sea Research 48: 197-207. 
Verfaillie, E., V. Van Lancker \& M. Van Meirvenne, 2006. Multivariate geostatistics for the predictive modelling of the surficial sand distribution in shelf seas. Continental Shelf Research 26: 2454-2468.

Wentworth, C. K., 1922. A scale of grade and class terms for clastic sediments. The Journal of Geology 30: 377-392.

Winterwerp, J. C. \& W. G. M. van Kesteren, 2004. Introduction to the Physics of Cohesive Sediment in Marine Environment. Elsevier B.V., Amsterdam.

Wollast, R., K. H. Brink \& A. R. Robinson, 1998. Evaluation and Comparison of the Global Carbon Cycle in the Coastal Zone and in the Open Ocean. The sea: The Global Coastal Ocean: Processes and Methods. Wiley, New York: 213-252.
Wood, S. N., 2003. Thin plate regression splines. Journal of the Royal Statistical Society, Series B (Statistical Methodology) 65(1): 95-114.

Young, A., 2007. MESH maps come online. a framework to support seabed habitat mapping. Hydro International 11: 6-9.

Zuur, A. F., E. N. Ieno \& C. S. Elphick, 2010. A protocol for data exploration to avoid common statistical problems. Methods in Ecology \& Evolution 1: 3-14.

Zuur, A. F., E. N. Ieno \& G. M. Smith, 2007. Analysing Ecological Data. Springer, New York: 467-472. 